\author{
RESEARCH ARTICLE \\ 10.1029/2020JC016518 \\ Key Points: \\ - Marine heatwaves in the ECS and \\ SYS during 2016-2018 summers \\ were caused by shortwave radiation, \\ current, and vertical mixing \\ anomalies \\ - Shortwave radiation increases in \\ summers were due to reductions of \\ the cloud cover, closely related to the \\ East Asian Summer Monsoon \\ variability \\ - An anticyclonic eddy in SYS in \\ summer 2018, driven by regional \\ wind anomalies, played a significant \\ role in trapping anomalous heat
}

Supporting Information:

- Supporting Information S1

Correspondence to:

M. Feng and B. Yin,

ming.feng@csiro.au;

bsyin@qdio.ac.cn

Citation:

Gao, G., Marin, M., Feng, M., Yin, B., Yang, D., Feng, X., et al. (2020). Drivers of marine heatwaves in the East China Sea and the South Yellow Sea in three consecutive summers during 20162018. Journal of Geophysical Research: Oceans, 125, e2020JC016518. https:// doi.org/10.1029/2020JC016518

Received 17 JUN 2020 Accepted 24 JUN 2020

Accepted article online 1 JUL 2020

(C)2020. American Geophysical Union. All Rights Reserved.

\section{Drivers of Marine Heatwaves in the East China Sea and the South Yellow Sea in Three Consecutive Summers During 2016-2018}

\author{
Guandong Gao ${ }^{1,2,3}$, Maxime Marin ${ }^{4,5}$ (D), Ming Feng ${ }^{4}$ (D), Baoshu Yin ${ }^{1,2,3,6}$ (D), Dezhou Yang ${ }^{1,2,3}$ (D), \\ Xingru Feng ${ }^{1,2,3}\left(\mathbb{D}\right.$, Yang Ding ${ }^{7,2}\left(\mathbb{D}\right.$, and Dehai Song ${ }^{7,2}(\mathbb{D})$ \\ ${ }^{1}$ Key Laboratory of Ocean Circulation and Waves, Institute of Oceanology Chinese Academy of Sciences, Qingdao, China, \\ ${ }^{2}$ Qingdao National Laboratory for Marine Science and Technology, Qingdao, China, ${ }^{3}$ Center for Mega Science, Chinese \\ Academy of Science, Qingdao, China, ${ }^{4}$ CSIRO Oceans and Atmosphere, Crawley, Western Australia, Australia, ${ }^{5}$ Institute \\ for Marine and Antarctic Studies, University of Tasmania, Hobart, Tasmania, Australia, ${ }^{6}$ University of Chinese Academy \\ of Sciences, Beijing, China, ${ }^{7}$ Key Laboratory of Physical Oceanography, Ministry of Education, Ocean University of China, \\ Qingdao, China
}

Abstract In 3 consecutive years from 2016 to 2018, extreme ocean warming events, or marine heatwaves (MHWs), occurred during boreal summers in the East China Sea (ECS) and South Yellow Sea (SYS), which is unprecedented in the past four decades based on the satellite record. In this study, we used a high-resolution hydrodynamic model based on Finite Volume Community Ocean Model (FVCOM) to simulate the evolution of these warming events. An upper ocean temperature budget (0-20 m) analysis based on the model results shows that the shortwave radiation and the ocean advection anomalies jointly contributed to the anomalous warming in the three successive summers (June-August) in the SYS and the north part of the ECS. In addition, the reduction of surface wind speeds during the 2016 and 2017 summers further weakened the vertical mixing, thereby enhancing the anomalous warming in the north part of the ECS adjacent to the SYS. During the three summers, the increases of shortwave radiation were closely related to the East Asian Summer Monsoon (EASM) variability, which reduced the cloud cover in the ECS and SYS, whereas the advection anomalies were mostly associated with regional wind anomalies. In summer 2018, upper ocean heat was transported into the central trough of the SYS, accumulated in an anticyclonic eddy generated by the anomalous wind stress curls. Therefore, despite the primary driver of the MHWs is the EASM variation, regional processes are critical to driving the spatial pattern of the MHW intensity in the ECS and SYS.

Plain Language Summary Marine heatwaves, known as periods of extreme warming at the sea surface, can last for days to months and cause damages to the marine environment and marine life. In the East China Sea and the South Yellow Sea, the frequent occurrences of harmful algae blooms are often associated with marine heatwaves. Satellite data reveal that marine heatwaves occurred in the East China Sea and the South Yellow Sea during the three boreal summers from 2016 to 2018, which is unprecedented in the past four decades. Using a numerical model of the ocean, we examined the marine heatwaves during these three successive summers. We show that the increased solar radiation, ocean current anomalies, and reduced vertical mixing were three critical factors for the warming events in the three summers.

This study helps the fisheries and aquaculture industries in the East China Sea and the South Yellow Sea to better manage the environmental risks under a warming climate by predictions of marine heatwaves.

\section{Introduction}

The occurrences of extreme warming events in the world oceans, the marine heatwaves (MHWs; Hobday et al., 2016), are becoming more frequent in the recent decade. There have been recorded MHW events in coastal waters off Australia (Benthuysen et al., 2014, 2018; Feng et al., 2013; Oliver et al., 2017), the northern Mediterranean Sea (Olita et al., 2006; Sparnocchia et al., 2006), the northwest Atlantic (K. Chen et al., 2014), the northeast Pacific (Bond et al., 2015; Di Lorenzo \& Mantua, 2016), and coastal waters off South Africa (Schlegel et al., 2017). MHW events have drawn great attentions due to their extraordinary influences on 
(a)

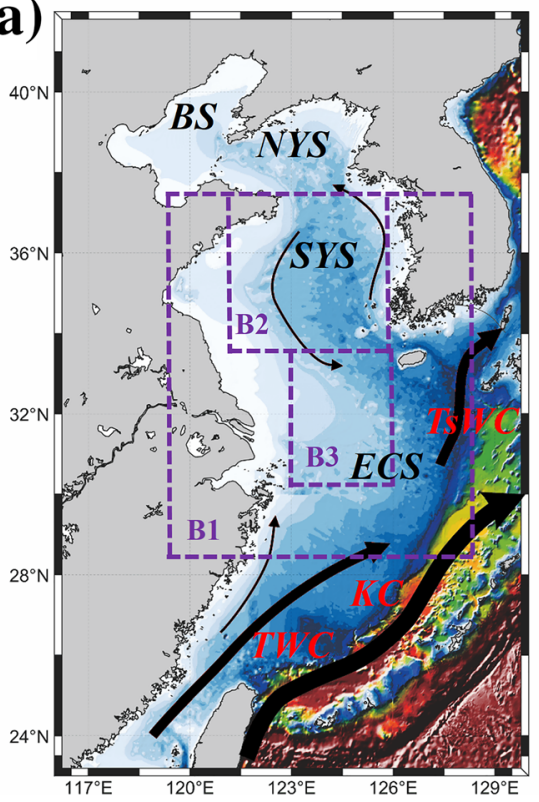

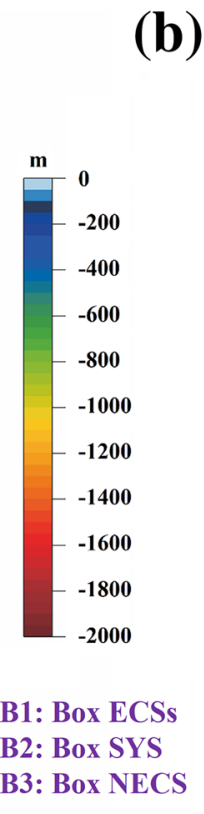

(b)

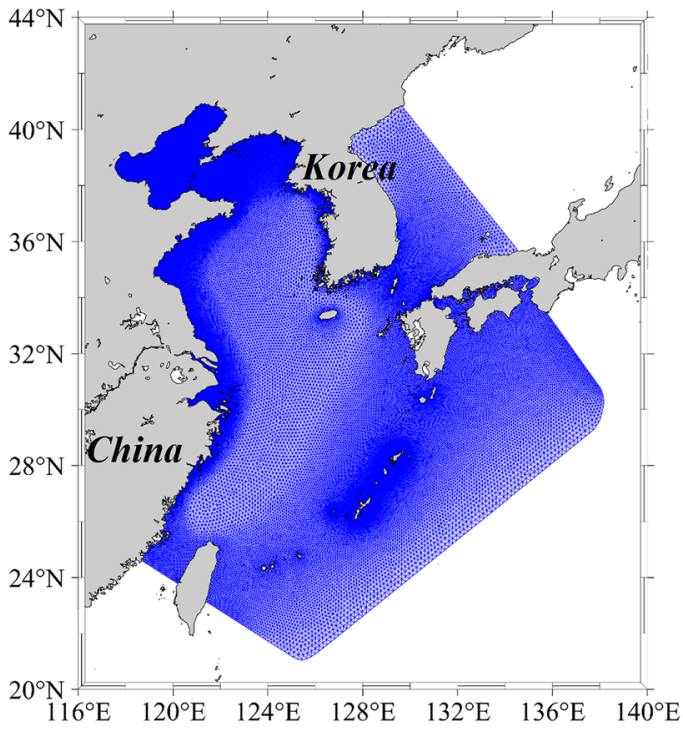

Figure 1. (a) Map of the Bohai Sea (BS), North Yellow Sea (NYS), South Yellow Sea (SYS) and East China Sea (ECS), with topography and main current patterns. (b) The FVCOM-ECSs model domain and mesh grid used in this study. TsWC, TWC, and KC represent Tsushima Warm Current, Taiwan Warm Current, and Kuroshio Current, respectively. Boxes ECSs $\left(119-126.5^{\circ} \mathrm{E}, 28.75-36.65^{\circ} \mathrm{N}\right)$, SYS $\left(121-125.9^{\circ} \mathrm{E}, 33.65-37.4^{\circ} \mathrm{N}\right)$, and NECS $\left(123-126^{\circ} \mathrm{E}, 30-33.65^{\circ} \mathrm{N}\right)$ are indicated in (a) with purple dashed lines, which are the domain where the MHWs are discussed in this study.

the regional biodiversity and mortality of commercial fisheries (Caputi et al., 2016; Mills et al., 2012; Oliver et al., 2017).

There have also been observations of extreme MHW events occurring in the East China Sea (ECS; Tan \& Cai, 2018) and the Yellow Sea in recent years. As a marginal sea of the Pacific Ocean, the ECS is connected to the South Yellow Sea (SYS) to the north (along a section from the mouth of the Changjiang River, China to Jeju Island, Korea) and is separated from the South China Sea and the Philippine Sea by the Taiwan Strait and the Ryukyu Islands (Figure 1). The ECS and the SYS are known as one of the most developed continental shelf areas globally (Yanagi \& Takahashi, 1993), and they are referred to as the ECS system (ECSs) in this study.

In the ECSs, the frequent occurrences of harmful algae blooms are associated to anomalous warm conditions or MHWs (Cai et al., 2016). The anomalous warming would enhance stratification and restrict phytoplankton in the top of water column where more light is available for them to thrive. In addition, anomalous warming in late spring and early summer greatly reduces the abundance of warm-water species of zooplankton like $C$. sinicus, which in turn reduces grazing pressure on phytoplankton and stimulates phytoplankton or harmful algae blooms (Cai et al., 2016). Such blooms significantly lower the oxygen levels and consequently result in the spreading of coastal hypoxic zone, endangering coastal and marine ecosystems (Cai et al., 2016). Hence, it is crucial to investigate the characteristics and controlling mechanisms of MHWs in the ECSs.

The ECSs has experienced steady warming trends during the recent four decades (Cai et al., 2017; Oey et al., 2013; Yeh \& Kim, 2010). Both Yeh and Kim (2010) and Oey et al. (2013) studied the decadal warming and its drivers during winter, whereas Cai et al. (2017) investigated the interdecadal warming during both winter and summer. Nevertheless, event-specific studies about MHWs in ECSs are rare. In August 2016, record-breaking monthly mean sea surface temperature (SST) emerged in the ECS, as indicated in the National Oceanic and Atmospheric Administration's Optimum Interpolation Sea Surface Temperature (NOAA OISST) data (Tan \& Cai, 2018). Strikingly, the NOAA OISST data show that SST anomalies in August 2017 were even stronger and covered wider areas in the ECSs, followed with another warm summer in 2018. Three successive warm summers, including two record-breaking ones, are unprecedented in the 
past four decades, which motivates us to examine the anomalous atmospheric and oceanic conditions responsible for those MHWs.

The summer circulation system in the ECSs mainly consists of cyclonic (anticlockwise) circulation over the SYS (Beardsley et al., 1992; Xia et al., 2006; Yanagi \& Takahashi, 1993) and the Taiwan warm current (TWC) and Tsushima warm current (TsWC) (Isobe, 2004, 2008) and the Kuroshio current (KC) (Wang \& Oey, 2014; D. Z. Yang et al., 2018) in the ECS. There are also the northward Chinese coastal currents (Naimie et al., 2001). National Center for Environmental Prediction (NCEP) or European Centre for MediumRange Weather Forecasts (ECMWF) reanalysis data set is useful in exploring the warming trend of ECSs on long time scales (Cai et al., 2017; Oey et al., 2013; K. A. Park et al., 2015; Yeh \& Kim, 2010), but they lack spatial resolution to capture the complicated current system in the ECSs. What is more, tides, which are important to the hydrodynamics in the ECSs (e.g. Lozovatsky et al., 2007a, 2007b; Naimie et al., 2001; Xia et al., 2006), are not considered in the NCEP and ECWMF products. Therefore, ocean processes with respect to the warm summers during 2016-2018 may not be well quantified by these reanalysis products (Tan \& Cai, 2018). A well-validated regional model with high spatial resolution would be crucial to reproduce the anomalous warming patterns, thereby quantifying the contribution of responsible processes with better accuracy (Frölicher et al., 2018).

Major processes controlling summer surface temperature variations in the ECSs include heat advection by the ocean currents (Tan \& Cai, 2018), air-sea heat flux, mainly controlled by the East Asian Summer Monsoon (EASM) (Cai et al., 2017; Oey et al., 2013) and the Western Pacific Subtropical High (WPSH) (Matsumura et al., 2015; Tan \& Cai, 2018), and local vertical mixing (Xie et al., 2002). Different MHW events may involve different combinations of the processes. The aim of this study is to examine the processes responsible for three successive warm summers (June, July, and August; JJA hereafter) in the ECSs by analyzing regional ocean model results.

The rest of the paper is organized as follows. The data, numerical modeling, and analysis method are introduced in section 2. Section 3 presents the details of temperature budget analysis and the major drivers. Section 4 summarizes the main findings.

\section{Data and Methods}

\subsection{SST Data}

The SST data used for the validation of numerical model results in this study are NOAA OISST version 2 (Reynolds et al., 2007), which is a daily and $0.25^{\circ} \times 0.25^{\circ}$ gridded product of Advanced Very High Resolution Radiometer (AVHRR) satellite data provided by the NOAA/OAR/ESRL PSD, Boulder, Colorado, USA, accessed from their website at https://www.esrl.noaa.gov/psd/. Satellite bias was corrected with respect to in situ data from ships and buoys (Reynolds et al., 2007). Data are available from 1 September 1981 to present.

\subsection{Atmospheric Data}

To investigate the role and contribution of atmospheric and radiative forcing to the three consecutive warm summers, we used data from the NCEP Climate Forecast System Reanalysis version 2 product (CFSRv2; Saha et al., 2013). CFSRv2 is the reanalysis product of the fully coupled atmosphere-ocean-land model Climate Forecast System version 2 (CFSv2) implemented in March 2011. It uses the NCEP Global Forecast System (GFS) as its atmospheric model and the Modular Ocean Model, version 3 (MOM3), from the Geophysical Fluid Dynamics Laboratory (GFDL). CFSv2 includes two data assimilation systems namely the NCEP-Department of Energy (DOE) Global Reanalysis 2 (Kanamitsu et al., 2002) and the Global Ocean Data Assimilation System (GODAS; Behringer, 2007). Data used in this study include hourly 10-m winds, surface air temperature, air pressure and relative humidity, downward longwave and shortwave radiations at the surface, and precipitation rates and geopotential height at 850 and $500 \mathrm{hPa}$ on a $0.2^{\circ} \times 0.2^{\circ}$ spatial grid. Monthly outputs of the first version of CFSR (Saha et al., 2010) at a resolution of $0.312^{\circ} \times 0.312^{\circ}$ were used to compare recent atmospheric conditions with the long-term climatology. 


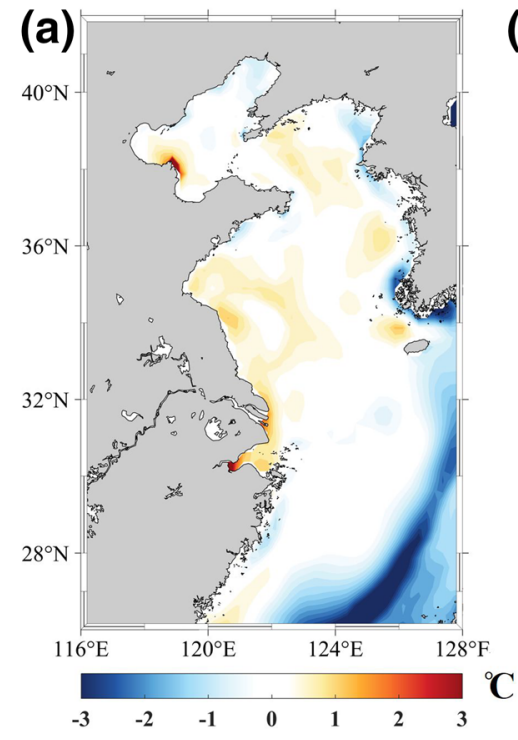

Bias

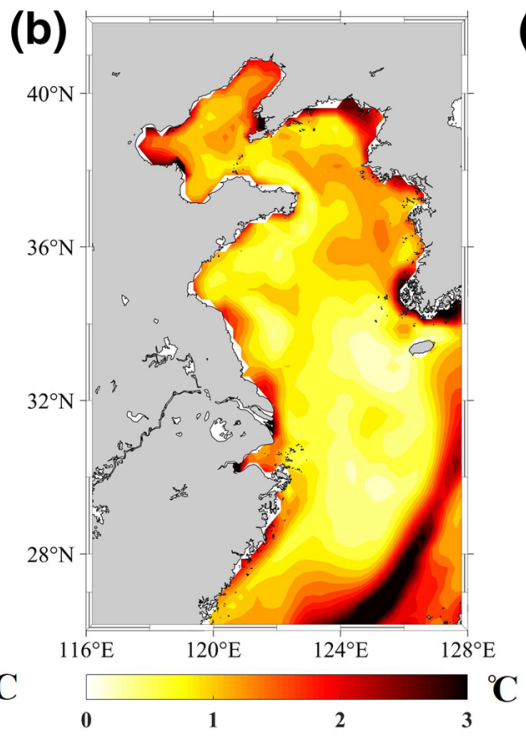

RMSE

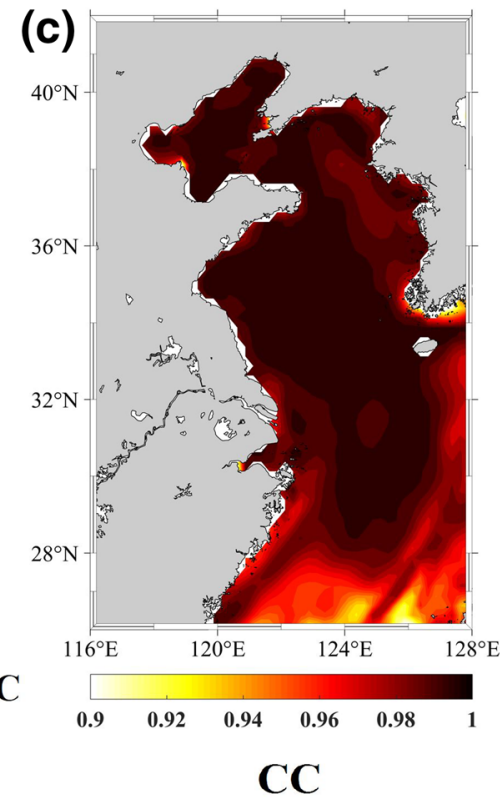

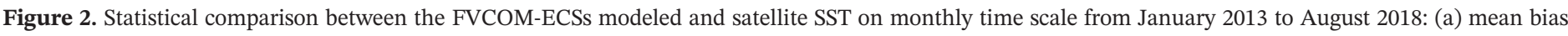

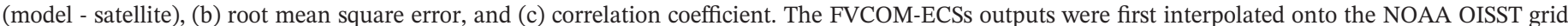
before the mean bias, RMSE (root mean square error), and correlation coefficients between satellite and the FVCOM-ECSs SST were computed. The FVCOM-ECSs SST was taken from the temperature output from the first sigma layer.

\subsection{Numerical Modeling \\ 2.3.1. Model Setup}

The unstructured-grid Finite Volume Community Ocean Model (FVCOM; C. Chen et al., 2003) is used. The model mesh and configuration used in the study are the same as those in Ding et al. (2018) and Ding et al. (2019), which investigated coastally trapped waves and ocean current fluctuations under storms in the ECSs. In this study, the model is named as FVCOM-ECSs.

The FVCOM-ECSs mesh consists of 70,479 nodes and 136,612 elements, covering the Bohai Sea (BS), the North Yellow Sea (NYS), the SYS, and the ECS (Figure 1b). The horizontal resolution increases gradually from $20 \mathrm{~km}$ near the open boundary to around $1 \mathrm{~km}$ in the coastal regions. In the vertical direction, 30 sigma layers are evenly distributed in the terrain-following coordinate. The bathymetry data used in this model are primarily obtained from DBDB5 (U.S. Naval Oceanographic Office, 1983), combined with topography data from the China coastal sea chart database to gain higher resolutions along the Chinese coast. The wet and dry treatment is embedded in the model. The vertical eddy viscosity is calculated using Mellor and Yamada (1982) turbulent closure model, and the horizontal diffusion coefficient is determined by Smagorinsky eddy parameterization method (Smagorinsky, 1963).

In the FVCOM-ECSs, the open boundary forcing such as subtidal sea surface heights, currents, temperature, and salinity on daily time scales was derived from the global model of Estimating the Circulation and Climate of the Ocean Phase II (ECCO2; Menemenlis et al., 2008). Hourly tidal levels and barotropic tidal currents were obtained from TPXO 7.2 based on nine tidal constituents $\left(\mathrm{M}_{2}, \mathrm{~S}_{2}, \mathrm{~N}_{2}, \mathrm{~K}_{1}, \mathrm{O}_{1}, \mathrm{Q}_{1}, \mathrm{M}_{4}, \mathrm{MS}_{4}\right.$, and $\mathrm{MN}_{4}$ ). The global ECCO2 model outputs were also used for the initial temperature and salinity fields of the FVCOM-ECSs. The ECCO2 data can be derived from the Asia-Pacific Data-Research Center of the IPRC (APDRC; http://apdrc.soest.hawaii.edu/index.php). Surface forcing data acquired from CFSRv2 were hourly 10-m winds, surface air temperature and relative humidity, downward longwave and shortwave radiations at the surface, and precipitation rates. Latent heat flux and sensible heat flux were calculated using bulk formulation (Fairall et al., 1996; subroutine COARE26Z in FVCOM 3.2.2). Two major rivers (Changjiang River and Yellow River) were considered: the temperature was specified referring to daily Multi-sensor Ultra-high Resolution (MUR) SST; the salinity was set to be constant at 5 psu; monthly 

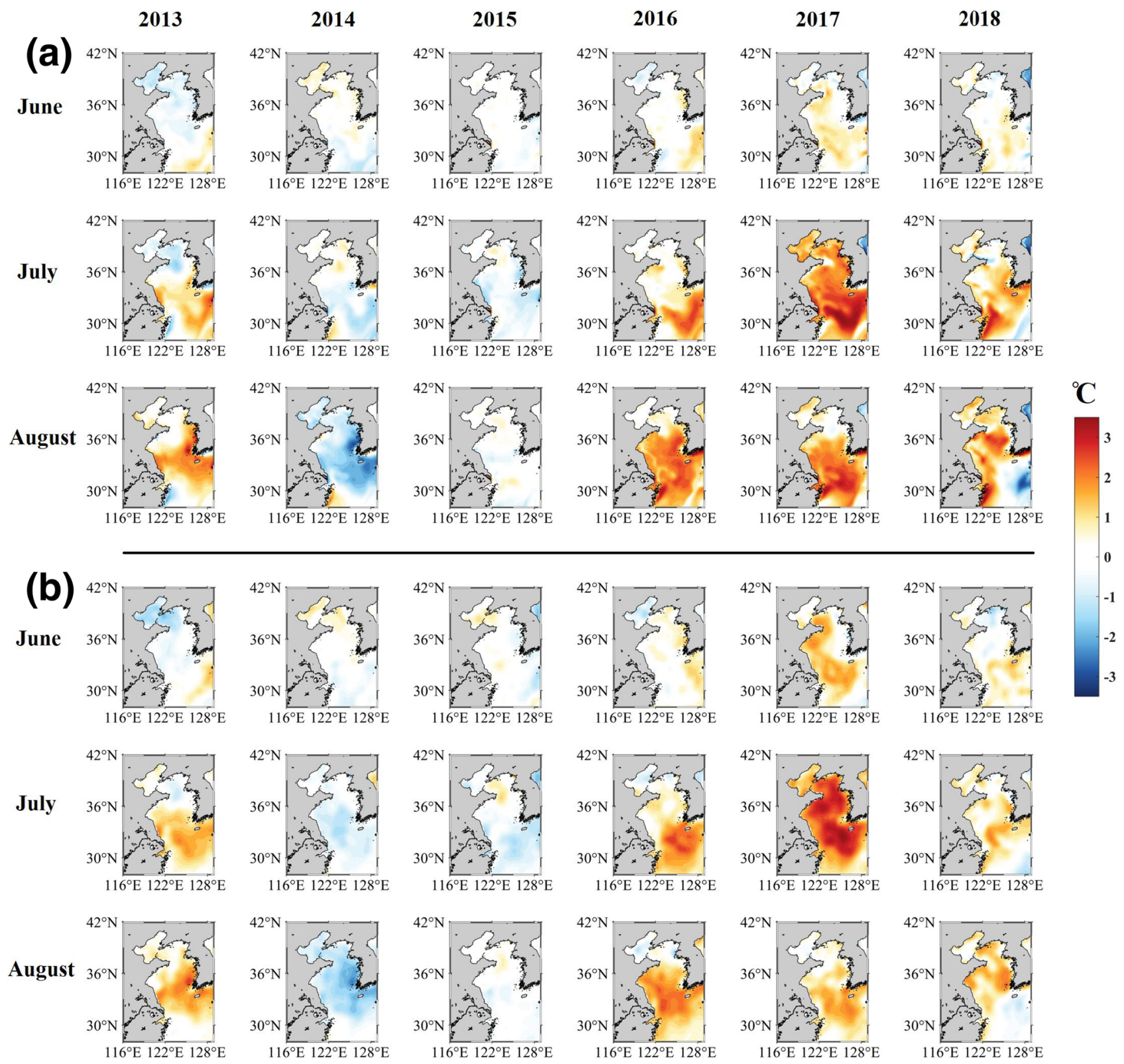

Figure 3. (a) The FVCOM-ECSs modeled and (b) satellite (monthly-mean) SST anomalies in the ECSs in June, July, and August during $2013-2018$.

averaged freshwater discharge data were provided by the Information Center of Water Resources, Bureau of Hydrology, Ministry of Water Resources of P. R. China.

The external and internal time steps are 5 and $50 \mathrm{~s}$, respectively. The model run was carried out from 1 January 2012 to 31 August 2018. The first year was regarded as spin up and model outputs from 1 January 2013 were analyzed.

\subsubsection{Model Validation}

The FVCOM-ECSs has been extensively validated in terms of barotropic tides, subtidal sea levels and currents, temperature, salinity, and surface waves (Ding et al., 2011, 2018, 2019; G. D. Gao et al., 2018). Here, we focus on the validation of the model SST variability by comparing with the NOAA OISST.

Compared with satellite observations, the FVCOM-ECSs SST has a mean bias around $0.2^{\circ} \mathrm{C}$, with RMSE smaller than $0.8^{\circ} \mathrm{C}$ in most parts of the study area (Figures $2 \mathrm{a}$ and $2 \mathrm{~b}$ ). The correlation coefficients 


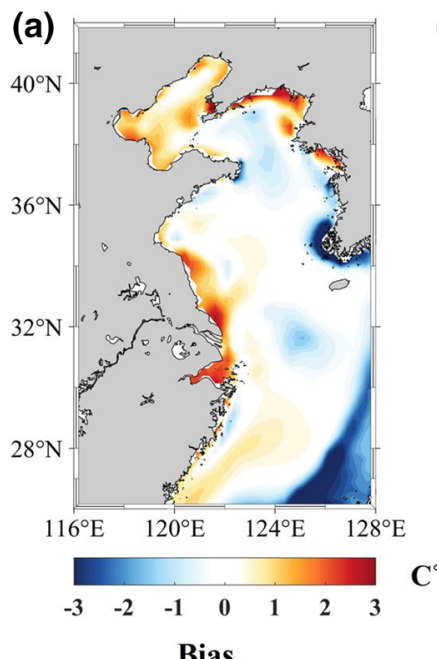

Bias
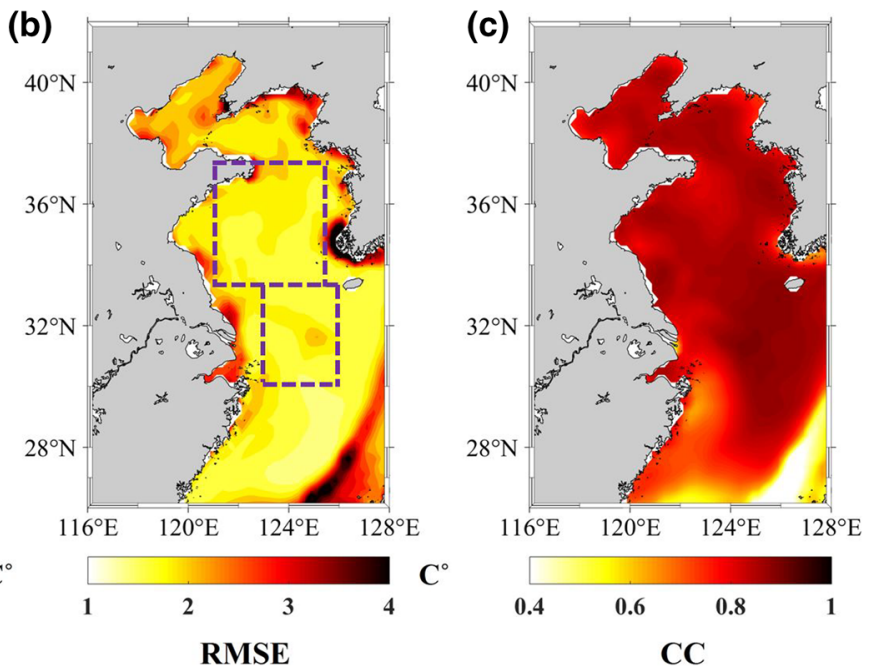

Figure 4. Statistical comparison between the FVCOM-ECSs modeled and satellite SST on daily time scale in JJA from 2013 to 2018: (a) mean bias (model - satellite), (b) root mean square error, and (c) correlation coefficient.

between the satellite and FVCOM-ECSs SST are above 0.95 in most of the ECSs (Figure 2c). Thus, the FVCOM-ECSs has reproduced the observed SST variability (Figure 3).

Three-year (2013-2015) averaged model results were used as the normal-year average or baseline reference in this study. The 2013-2015 averaged SST is quite similar to the long-term (1982-2016) averaged SST (Figure S1 in the supporting information), so it is reasonable to use the 3-year average as the baseline reference. Figure 3 shows that the FVCOM-ECSs successfully captured the position and strength of SST anomalies (relative to the normal-year average) from 2013 to 2018: one warm summer in 2013, two neutral
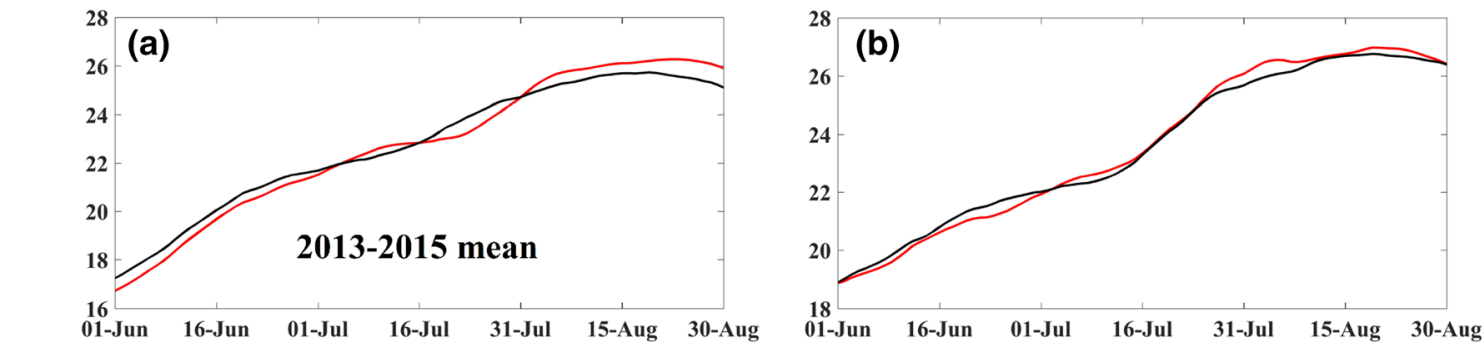

\section{4 (c) 二 Model \\ 2016 anomaly}$$
-2
$$
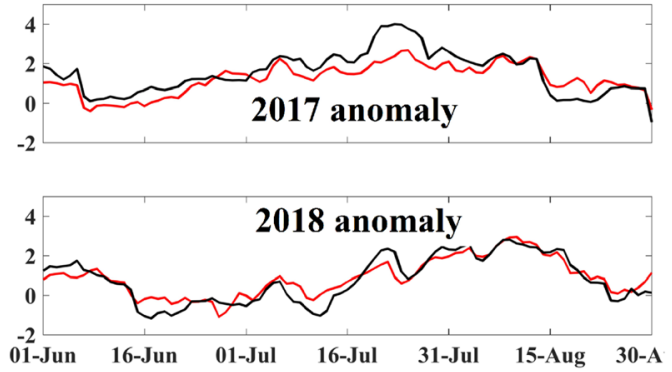
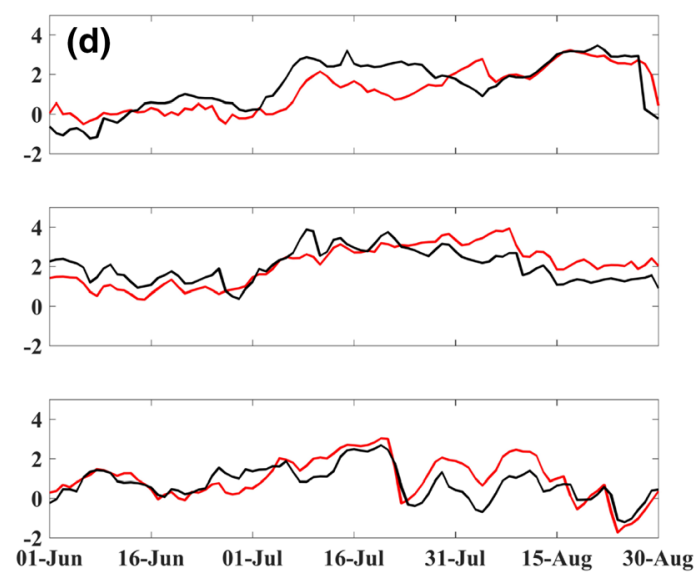

Figure 5. Comparison of normal-year (2013-2015) averaged and anomalous (2016-2018) SST during JJA for Boxes (a and c) SYS and (b and d) NECS. 

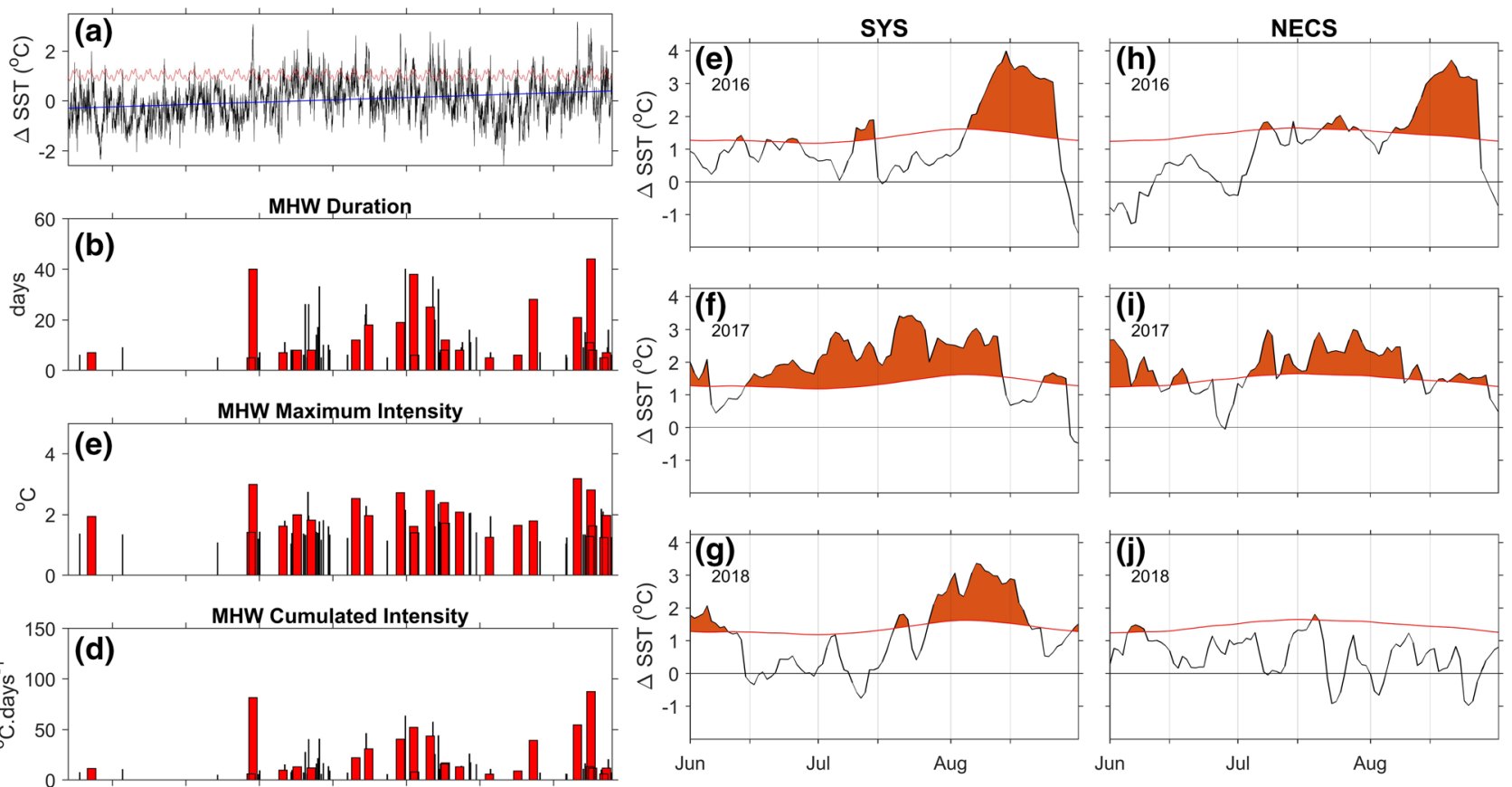

Figure 6. SST and MHW characteristics in the ECSs. (a) Time series of SST anomalies relative to the 1982-2016 climatology. The red and blue lines denote the MHW threshold and a linear trend, respectively. (b) MHW duration, (c) maximum intensity, and (d) cumulated intensity during 1982-2018. MHWs occurring in summer (June-August) were plotted in red. (e-j) Zoomed-in SST anomalies during the (top) 2016, (middle) 2017, and (bottom) 2018 summer averaged in the (e-g) SYS and (h-j) NECS box, respectively (Figure 1a). MHW threshold (orange line) and SST anomalies exceeding the MHW threshold value (shading) were denoted.

summers in 2014 (slightly cold) and 2015, and three consecutive warm summers from 2016 to 2018. Anomalous warm SSTs were primarily located in the SYS and the north part of the ECS. In July 2017, positive SST anomalies were the highest and covered the largest area.

During summers (JJA) from 2013 to 2018 (Figure 4), the FVCOM-ECSs could reproduce daily SST variations in most parts of the study domain, except in the near shore areas and in the KC region. Two boxes (Boxes SYS and NECS), with strong SST anomalies and good model performances (Figures 2-4), are used for heat balance analysis. Box SYS covers the China shelf and the center trough of the SYS $\left(121-125.9^{\circ} \mathrm{E}, 33.65-\right.$ $37.4^{\circ} \mathrm{N}$ ), and Box NECS is the central shelf of the ECS, located in the north part of ECS adjacent to the SYS $\left(123-126^{\circ} \mathrm{E}, 30-33.65^{\circ} \mathrm{N}\right)$. The model accurately reproduced the observed normal-year average (20132015 mean) SST evolution in Boxes SYS and NECS, as shown in an 11-day running mean (Figures 5a and $5 b)$. The SST anomalies relative to normal-year average are also compared well with observations for both Boxes in 2016, 2017, and 2018 (Figures 5c and 5d). For Box SYS, the modeled SST anomalies generally agreed well with satellite data during JJA in 2016 and 2018, whereas the peak SST anomalies in July 2017 were underestimated by the model. For Box NECS, in 2017 and 2018, the model simulated the increases of SST anomalies from 1 June to the peak values; however, it underestimated the decay of the SST anomalies after the peak; SST anomalies in 2016 experienced two peaks, and the model slightly underestimated the first peak but well captured the second peak. The direct comparison of daily SST in JJA during 2016-2018 between the model results and satellite data is provided in Figure S2. Overall, the model was able to reproduce the normal-year averaged SST and increasing trends of SST anomalies from the beginning of June to the MHW peaks for both Boxes SYS and NECS in 2016-2018.

\subsection{MHW Definition and Metrics}

Hobday et al. (2016) definition was used to characterize the MHW events in summers during 2016-2018; that is, a MHW is defined as an anomalously warm, discrete, and prolonged event, which can be quantitatively described as periods of time when daily temperatures are above a particular threshold for at least 5 days. The threshold is calculated as the 90th percentile of daily temperature variability across a $>30$-year period, 
within an 11-day window centered on a specific day of the year. This seasonally varying threshold allows for events to occur at any time of the year. Threshold and climatological values were derived using the NOAA OISST. Here, we chose a fixed baseline climatological period following Hobday et al. (2016). Due to the limited length of observation time series, it was not possible to adopt a moving baseline, as advocated for climate change studies (Jacox, 2019).

Three MHW metrics are used in the study: the duration (days between the start and end dates), the maximum intensity (maximum SST anomalies during a single event), and the cumulated intensity (sum of daily intensity anomalies measured in ${ }^{\circ} \mathrm{C}$ days).

\subsection{Upper Ocean Temperature Budget}

The upper ocean temperature budget is calculated with the volume-averaged temperature tendency equation from sea surface to a fixed depth $h$ and within a surface area $A$ (Benthuysen et al., 2014; Feng et al., 2008; Oliver et al., 2017).

$$
\underbrace{\frac{\partial\langle T\rangle}{\partial t}}_{R A T E_{v}}=\underbrace{-\left\langle u_{H} \cdot \nabla T\right\rangle}_{A d v_{H}} \underbrace{-\left\langle w \frac{\partial T}{\partial z}\right\rangle}_{A d v_{V}}+\underbrace{\frac{1}{\rho C_{P} A} \int^{A} \frac{Q}{h} d A}_{Q v} \underbrace{-\frac{1}{A h} \int^{A}\left(\kappa_{v} \frac{\partial T}{\partial z}\right)_{-h} d A}_{D i f_{V}} \underbrace{-\left\langle\nabla \cdot\left(\kappa_{h} \nabla T\right)\right\rangle}_{D i f_{H}}
$$

where $T$ is the temperature; $t$ is the time; $\langle\rangle=.\frac{1}{h A} \int^{A} \int_{-h}^{0} d z d A$ represents volume average; $u_{H}$ is the horizontal current vector; $\nabla$ is the horizontal gradient operator; $w$ is the vertical current; $Q=Q_{s w}(0)-Q_{s w}(h)+$ $Q_{l w}+Q_{l h}+Q_{s h}$ is the net heat flux which is the summation of shortwave radiation absorbed in the top layer $Q_{s w}(0)-Q_{s w}(h)$, longwave radiation $Q_{l w}$, latent heat flux $Q_{l h}$, and sensible heat flux $Q_{s h} . Q_{s w}(z)$ is the shortwave radiation penetrated at depth $z$ (see details in Paulson \& Simpson, 1977). $K_{v}$ and $K_{h}$ are the horizontal and vertical eddy diffusivities. The temporal change rate of volume-averaged temperature $R A T E_{V}$ is decomposed into following terms: horizontal advection $A d v_{H}$, vertical advection $A d v_{V}$, net heat flux $Q_{v}$, vertical diffusion $D i f_{V}$, and horizontal diffusion $D i f_{H}$. The model integrated the terms for the volume-averaged temperature tendency equation over every external time step $(5 \mathrm{~s})$ and recorded the output at daily interval.

The total advection $\left(A d v_{H}+A d v_{V}\right)$ was diagnostic output from the model; however, the directions were only distinguished into inward or outward the "tracer volume element" (see the finite volume method in C. Chen et al., 2013). Therefore, the advection contributions from the five boundaries of Boxes SYS and NECS were calculated based on daily-averaged temperature and current outputs from the model using a decomposition method (Feng et al., 2008; T. Lee et al., 2004; Zhang et al., 2018):

$$
\begin{aligned}
A d v_{H}+A d v_{v}= & \underbrace{\frac{1}{V} \iint_{S b} v_{\text {South }}\left(T_{\text {South }}-\left\langle T_{\text {Box }}\right\rangle\right) d x d z}_{\text {South }} \underbrace{-\frac{1}{V} \iint_{N b} v_{\text {North }}\left(T_{\text {North }}-\left\langle T_{\text {Box }}\right\rangle\right) d x d z}_{\text {North }} \\
& \underbrace{+\frac{1}{V} \iint_{W b} u_{\text {West }}\left(T_{\text {West }}-\left\langle T_{\text {Box }}\right\rangle\right) d y d z}_{\text {Eertical }} \underbrace{-\frac{1}{V} \iint_{E b} u_{\text {East }}\left(T_{\text {East }}-\left\langle T_{\text {Box }}\right\rangle\right) d y d z}_{\text {West }} \\
& \underbrace{+\frac{1}{V} \iint_{A} w_{-h}\left(T_{-h}-\left\langle T_{\text {Box }}\right\rangle\right) d x d y}_{\text {t }}+A d v_{-} r e s
\end{aligned}
$$

$\mathrm{Sb}$ (South), $\mathrm{Nb}$ (North), $\mathrm{Wb}$ (West), Eb (East), and Vertical represent the south, north, west, east, and vertical boundaries of a box, respectively. $T_{\text {South }}, T_{\text {North}}, T_{\text {West }}, T_{\text {East }}$, and $T_{-h}$ are daily-averaged temperature at south, north, west, east, and vertical boundaries. $T_{\text {Box }}$ is the daily-averaged temperature in a box, and $V$ is the volume of a box. $v_{\text {South }}$ and $v_{\text {North }}$ are daily-averaged meridional currents at south and north boundaries respectively, while $u_{\text {West }}$ and $u_{\text {East }}$ are daily-averaged zonal currents at west and east boundaries respectively. The residuals ( $A d v_{-} r e s$ ) in Equation 2 may come from the interpolation errors from unstructured grids into the regular boundaries. The advection decomposition has been widely used in heat budget 
analysis on different time scales (Asbjørnsen et al., 2019; Bond et al., 2015; Fathrio et al., 2017; Feng et al., 2008; Hristova et al., 2019; T. Lee et al., 2004; Zhang et al., 2018).

Advection-induced temperature anomalies are associated to the anomalies of currents and temperature. Following T. Lee et al. (2004), contributions of advection at any boundary can be further decomposed into (using the south boundary as an example)

$$
\begin{aligned}
\underbrace{\frac{1}{V} \iint_{S b} v_{\text {South }}\left(T_{\text {South }}-\left\langle T_{\text {Box }}\right\rangle\right) d x d z}_{\text {South }}= & \underbrace{\frac{1}{V} \iint_{S b} \bar{\nu}_{\text {South }}\left(\bar{T}_{\text {South }}-\left\langle\bar{T}_{\text {Box }}\right\rangle\right) d x d z}_{\text {Normal - year avergae }}+\underbrace{\frac{1}{V} \iint_{S b} v^{\prime} \text { South }\left(\bar{T}_{\text {South }}-\left\langle\bar{T}_{\text {Box }}\right\rangle\right) d x d z}_{\text {Current anomaly }} \\
& +\underbrace{\frac{1}{V} \iint_{S b} \bar{v}_{\text {South }}\left(T^{\prime}{ }_{\text {South }}-\left\langle T^{\prime}{ }_{\text {Box }}\right\rangle\right) d x d z}_{\text {Temperature anomaly }}+\underbrace{\frac{1}{V} \iint_{S b} v^{\prime}{ }_{\text {South }}\left(T^{\prime}{ }_{\text {South }}-\left\langle T^{\prime}{ }_{\text {Box }}\right\rangle\right) d x d z}_{\begin{array}{c}
\text { Current and tempearture } \\
\text { anomaly }
\end{array}}
\end{aligned}
$$

Over bar represents the normal-year (2013-2015) average, and prime represents the anomaly in an individual year from 2016 to 2018. The four terms in the right hand side of Equation 3 represent, respectively, the advection of mean temperature difference by mean flow (Normal-year average), the advection of mean temperature difference by anomalous flow (Current anomaly), the advection of anomalous temperature difference by mean flow (Temperature anomaly), and the advection of anomalous temperature difference by anomalous flow (Current and temperature nomaly) (T. Lee et al., 2004).

\section{Results}

\subsection{Characteristics of Three Successive Warm Summers From 2016 to 2018}

Figure 6 summarizes the MHW characteristics for the ECSs, derived from the OISST. In the large ECSs Box, both 2016 and 2017 summers had well-defined, unprecedented MHW events (Figures 6b-6d), in terms of maximum intensity $\left(3^{\circ} \mathrm{C}\right)$ in 2016 and in terms of duration and cumulated intensity (44 days and $85.5^{\circ} \mathrm{C}$ days) in 2017 . There was a strong summer MHW in 1994, nearing maximum values of duration, intensity, and cumulated intensity, which might be associated with the Asian heatwave during that summer (C. Park \& Schubert, 1994). MHWs during the 2018 summer were weaker than the two previous years, despite occurring at several short periods. Despite high values of MHW maximum intensity $\left(2^{\circ} \mathrm{C}\right), 2018$ summer events lasted less than 10 days, resulting in a weak cumulative intensity (Figures 6b-6d). Overall, more frequent summer MHW events occurred after 1997 (Figures 6b-6d). The decadal increase in MHW frequency is likely due to the long-term warming trend observed since the beginning of the 20th century (Oliver, 2019; Oliver et al., 2018), although there appears to be a halt in the warming trend in the ECSs box since the late 1990s (Figure 6a).

In both the SYS and the NECS boxes, the main 2016 summer MHW started in early August, with maximum SST anomalies peaked in the middle of the month, a few days earlier in the SYS than in the NECS, both reaching $\sim 4^{\circ} \mathrm{C}$. While temperatures were above the climatological average in the SYS at the start of the 2016 summer, there was a progressive warming of SSTs in the NECS, from a relatively cool state at the start of summer (Figures 6e and 6h). In 2017, SSTs were above the MHW threshold at the start of the summer for both boxes and remained above the threshold during most of the summer (Figures $6 \mathrm{f}$ and $6 \mathrm{i}$ ). The main event occurred in early June and late June for the SYS and NECS and lasted until mid-August. In the 2018 summer, temperatures in the NECS only briefly crossed the MHW threshold, not persistent enough to be classified as a MHW (Figure 6j). However, a strong MHW occurred in the SYS, starting late July and lasting for about 20 days (Figure $6 \mathrm{~g}$ ), with a maximum intensity of about $3^{\circ} \mathrm{C}$.

\subsection{Temperature Budget}

SST anomalies during 2016-2018 generally emerged in June and peaked in July or August so that we focused the upper ocean temperature budget analysis during the JJA period. In both Boxes SYS NECS (Figures S3 and S4), anomalous warmings were most significant in the top $20 \mathrm{~m}$ in the summers of 2016-2018. In 2018, the anomalous warming in Box SYS extended to the subsurface layer toward the end of summer. Subsurface warming was also present in Box NECS during the first half of summer 2017. In this study, we used $20 \mathrm{~m}$ as the control volume depth as follows: (1) the anomalous warmings were most significant in 


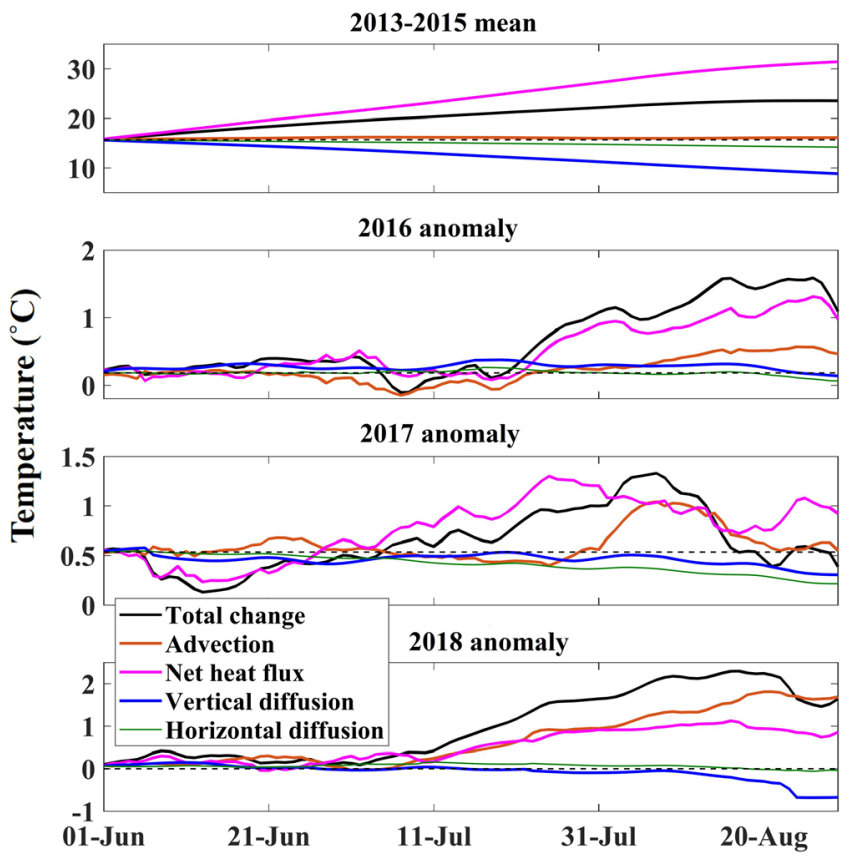

Figure 7. (a) Normal-year averages (2013-2015) and (b-d) anomalies (20162018) of temperature at the top $20 \mathrm{~m}$ for Box SYS in JJA caused by individual terms. Thin dash black lines indicate the temperature in (a) or temperature anomalies in (b) on 1 July. the top $20 \mathrm{~m}$ for both boxes; (2) $20 \mathrm{~m}$ reflects the summer mixed layer depth; and (3) the model SST agreed well with satellite data. In areas where water depth is shallower than $20 \mathrm{~m}$, the integration is between sea surface and sea floor. It is noted that water depths are deeper than $20 \mathrm{~m}$ in most areas in Boxes SYS and NECS.

\section{Box SYS}

During a normal year, the top 20-m temperature in the SYS box warmed up from about $16^{\circ} \mathrm{C}$ on 1 June to about $23^{\circ} \mathrm{C}$ toward the end of summer, with a $15^{\circ} \mathrm{C}$ warming contribution from the net air-sea heat flux, countered by an $\sim 7^{\circ} \mathrm{C}$ cooling from vertical mixing (Figure 7a).

Positive temperature anomalies in the SYS during summer 20162018 were mainly caused by the net air-sea heat flux and advection anomalies (Figures 7b-7d). In 2016, the anomalous net heat flux dominated the temperature variability; in 2017, net heat flux dominated in June and July, but the contribution of advection anomalies became important during the first half of August; in 2018, both the net heat flux and advection anomalies drove the rise of the temperature anomalies, with the advection effect more important in the second half of August. The initial temperature anomaly of $0.5^{\circ} \mathrm{C}$ on 1 June 2017 also contributed to the warm event during that summer.

In the air-sea heat flux, shortwave radiation dominated not only the temperature variation during a normal year but also the temperature anomalies during the three anomalous summers (Figures 8a-8d). Anomalous shortwave radiations warmed the SST during the whole JJA in 2017 and during the latter half of JJA in 2016 and 2018, whereas the other heat flux anomaly terms had weak warming or slightly cooling effects.

Anomalous heat advection across the south, west, and vertical (bottom) boundaries contributed to the summer warming in Box SYS in 2016 and 2017 (Figures 8f and 8g). The effects of advection were much more prominent in 2018: vertical advection anomalies and horizontal advection anomalies at the south boundary caused significant anomalous warmings in the second half of the 2018 summer (Figure 8h).

We further examined the causes of the peak temperature anomalies in Box SYS for the three summers (Table S1). The shortwave radiation was the most important factor, with contributions of $1.51^{\circ} \mathrm{C}, 0.8^{\circ} \mathrm{C}$, and $1.67^{\circ} \mathrm{C}$ during the summers in 2016,2017 , and 2018 , respectively. In 2018 , the contribution of advection to the peak temperature anomaly reached $1.55^{\circ} \mathrm{C}$, with $1.04^{\circ} \mathrm{C}$ and $0.72^{\circ} \mathrm{C}$ contributed across the vertical and south boundaries, respectively. Regression analysis shows that daily anomalous temperature changes were significantly correlated to both advection and shortwave radiation anomalies during JJA in Box SYS (Figure S5).

\section{Box NECS}

Whereas net air-sea heat flux and advection anomalies played critical roles in anomalous temperature changes in Box NECS, the role of vertical mixing also became important (Figures 9b-9d). Shortwave radiation anomalies still played a leading role among all the air-sea heat flux terms to warm the upper ocean (Figures 10b-10d). In 2016, shortwave radiation anomalies became significant from mid-August, while the reduction of latent heat loss provided additional warming effects (Figure 10b), as a result of reduced wind speeds compared to normal-year averages (Figure S6). In 2017, wind speeds were reduced, but the specific humidity was also reduced (Figure S7); thus, latent heat flux showed an overall cooling effect. The shortwave radiation anomalies were most significant in 2018, dominating over the other flux terms (Figure 10d).

Advection was important during summers in 2017 and 2018 (Figures $10 \mathrm{~g}$ and $10 \mathrm{~h}$ ), contributing to $0.84^{\circ} \mathrm{C}$ and $1.36^{\circ} \mathrm{C}$ of the peak temperature anomalies, respectively (Table S2). In 2016, temperature anomalies induced by advection were generally negative (Figure 10f). Whereas effects of advection at various 
2013-2015 mean

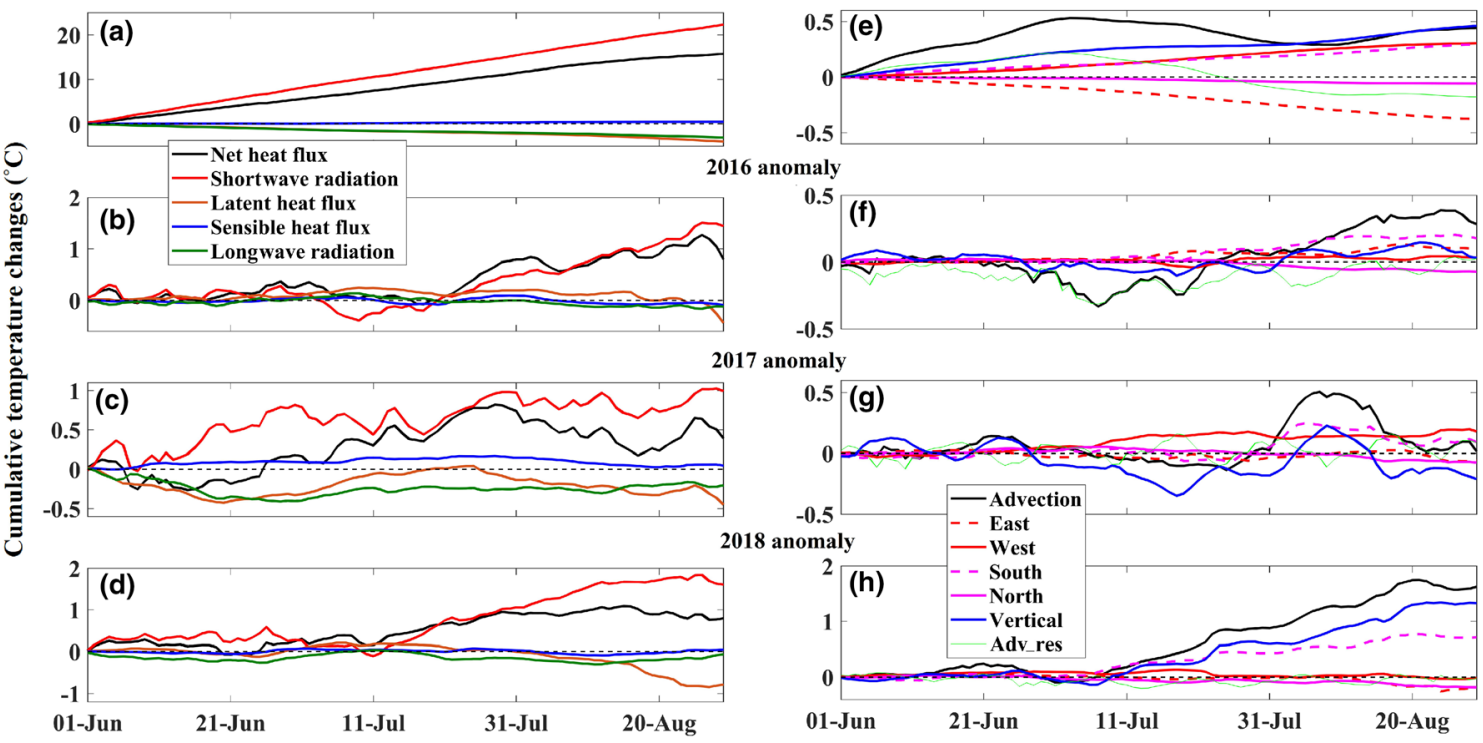

Figure 8. (a) Normal-year averages (2013-2015) and (b-d) anomalies (2016-2018) of cumulative temperature changes from 1 June at the top $20 \mathrm{~m}$ for Box SYS in JJA caused by each heat flux terms. (e) Normal-year averages and (f-h) anomalies of cumulative temperature changes from 1 June at the top $20 \mathrm{~m}$ for Box SYS caused by advection at various boundaries. Thin dash black lines indicates $0^{\circ} \mathrm{C}$.
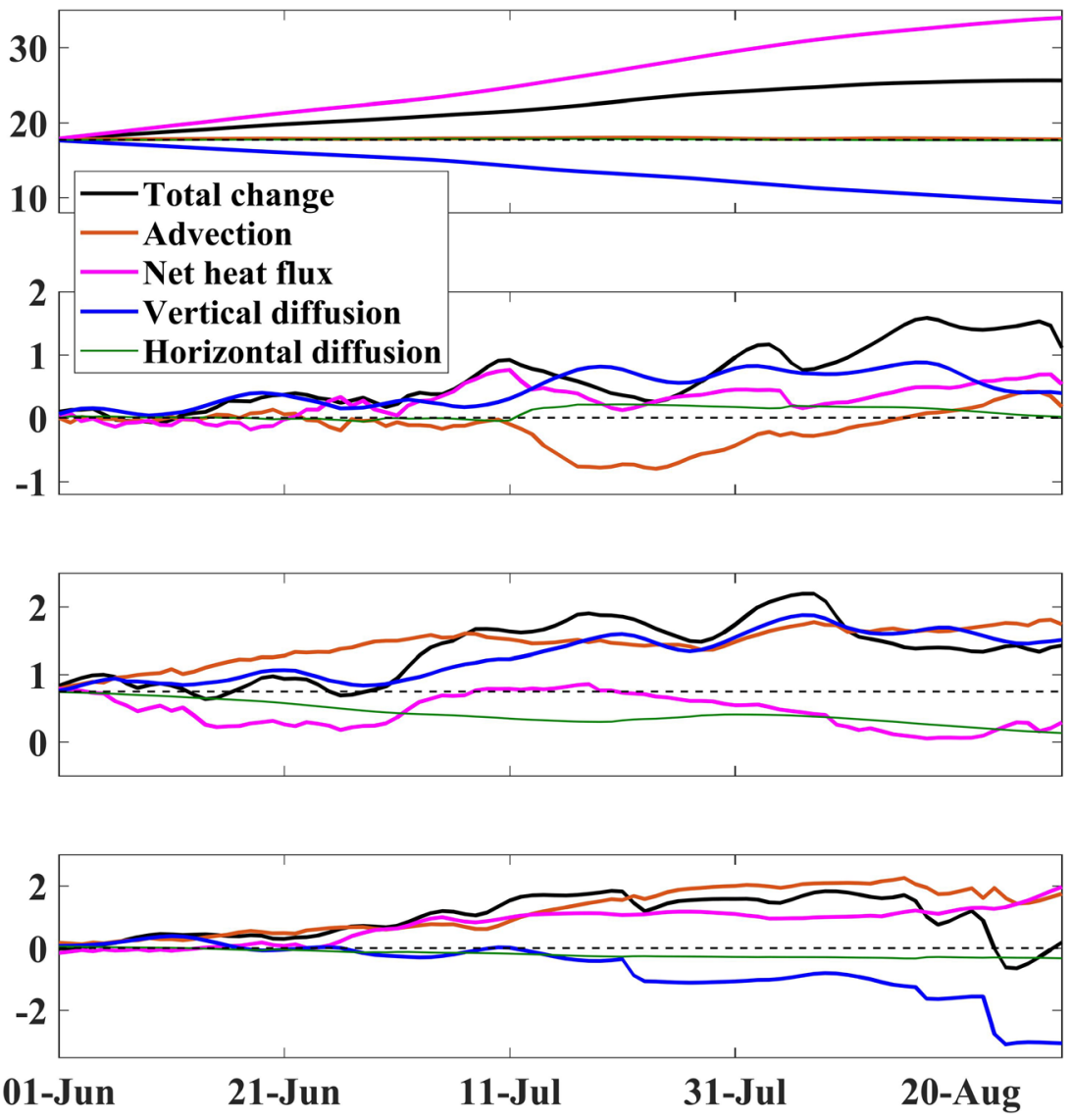

Figure 9. As in Figure 7 but for Box NECS. 
2013-2015 mean

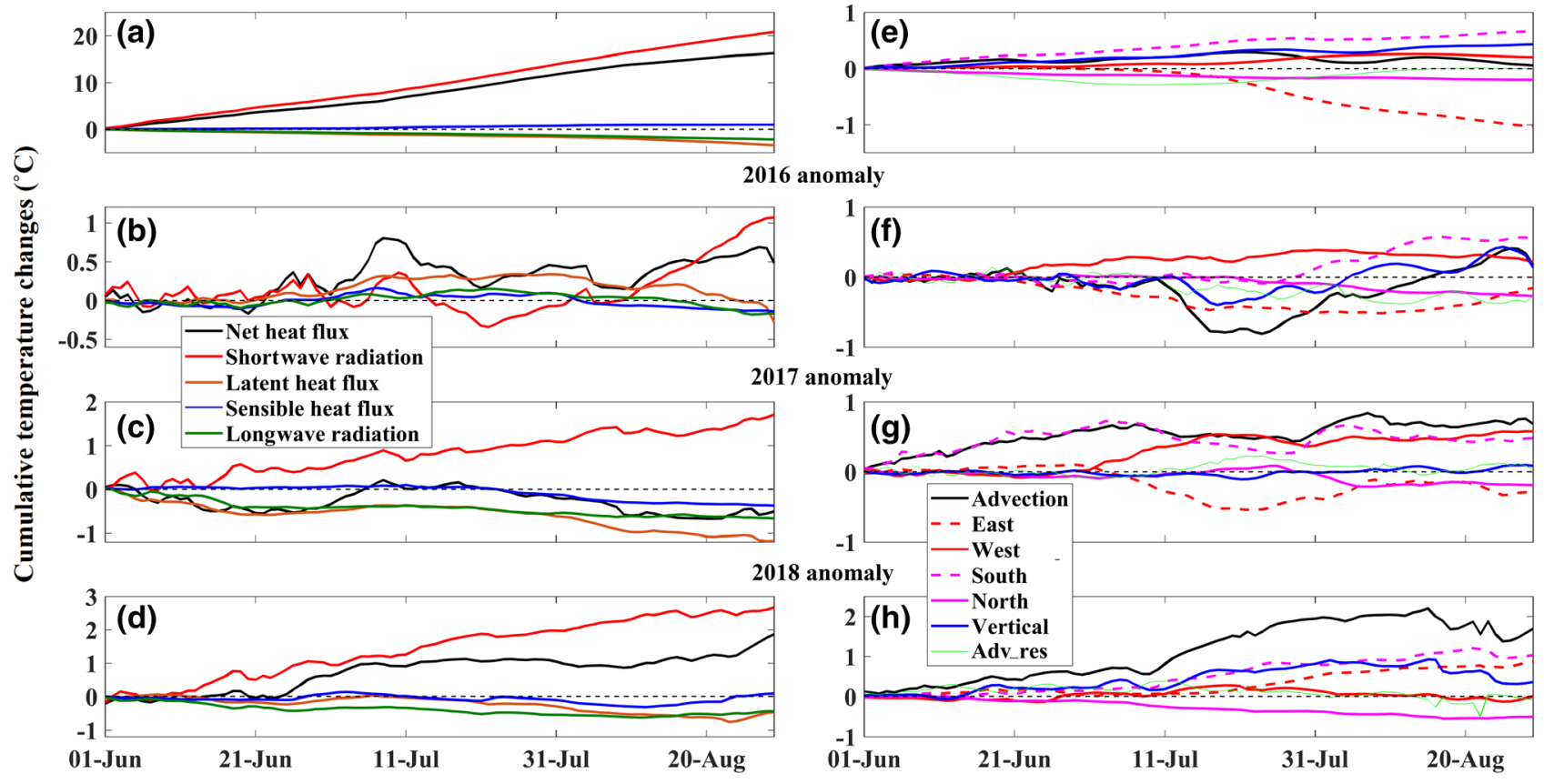

Figure 10. As in Figure 8 but for Box NECS.

boundaries were quite different among three summers, anomalous horizontal advection across the south boundary consistently contributed to warming events (Figures 10f-10h).

The reduction of vertical mixing was crucial to the summer warming in Box NECS in 2016 and 2017 (Figures $9 \mathrm{~b}$ and 9c). Vertical mixing contributed to $0.87^{\circ} \mathrm{C}$ and $1.12^{\circ} \mathrm{C}$ of the maximum surface temperature anomalies in 2016 and 2017, respectively, and the anomalies of daily temperature changes had significant correlations with that caused by vertical mixing variability (Figure S8).

In the next three subsections, we discuss the drivers of the anomalous increase of shortwave radiation, the ocean current anomalies, and the reduction of upper ocean vertical mixing in Box NECS.

\subsection{Shortwave Radiation}

Positive anomalies of shortwave radiations occurred during all three summers in 2016-2018, relative to 2013-2015 average, in a zonal band between $30^{\circ} \mathrm{N}$ and $35^{\circ} \mathrm{N}$ extending from eastern China to Japan (Figures 11a-11c). The magnitude and pattern of the positive anomalies of shortwave radiation remained the same when using a longer term climatology (Figure S9). The main weather system controlling cloud formation and rainfall in the ECS during summer is the EASM (Ding and Chan (2005). The onset of the EASM expresses itself as enhanced rainfalls in the South Asia region at the end of May, extending abruptly to the Yangtze River Basin in eastern China in early June. Monsoonal rain then moves northeastward toward the ECSs and the Korean Peninsula, expressed as a frontal cloud zone called the Meiyu-Baiu front/rainband (Ninomiya, 2004).

The mechanisms of the EASM variability are still not fully understood due to the complexity of the system. The primary external forcing for the onset of the EASM is believed to be the Pacific and Indian Ocean SST variations, as well as the snow cover on the Tibetan Plateau (Ding \& Chan, 2005; Zhou et al., 2009). However, internal variability of the regional atmospheric circulation determines the position and intensity of the cloud front. Pressure and wind anomalies at $850 \mathrm{hPa}$ showed a westward shift of the WPSH in 2016 and 2017 and a northward displacement of the WPSH in 2018 (Figures 11g-11i), as compared with climatology (Figure S10). The intensity and location of the WPSH are well correlated with the Meyiu-Baiu front activity and can represent leading EOF modes of the EASM (Huang et al., 2018; Oppenheim et al., 1999; B. Wang et al., 2013). The associated changes in low-level circulation likely modified the EASM intensity 


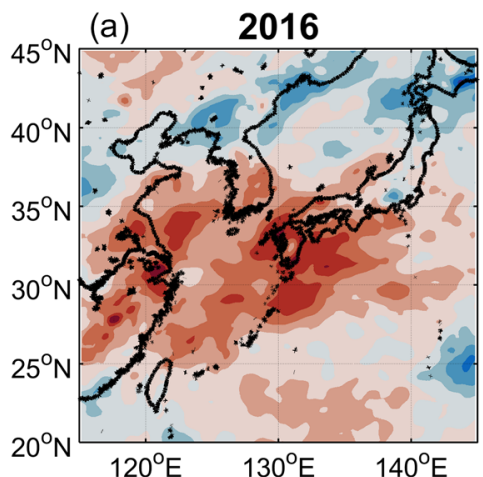

(d)

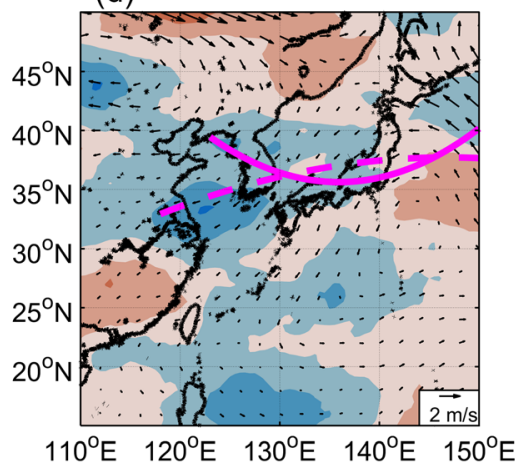

(g)

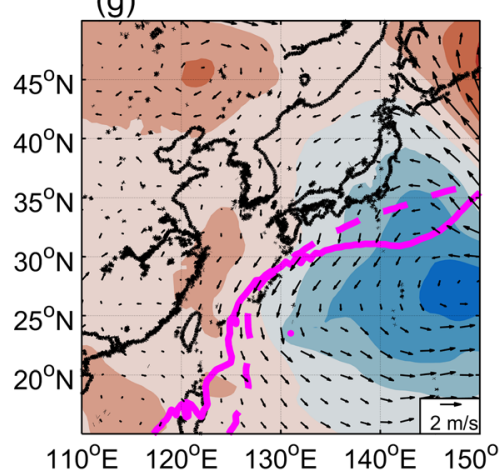

(b) $\quad 2017$

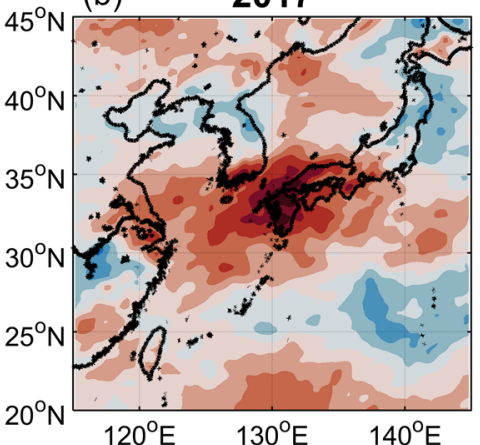

(e)

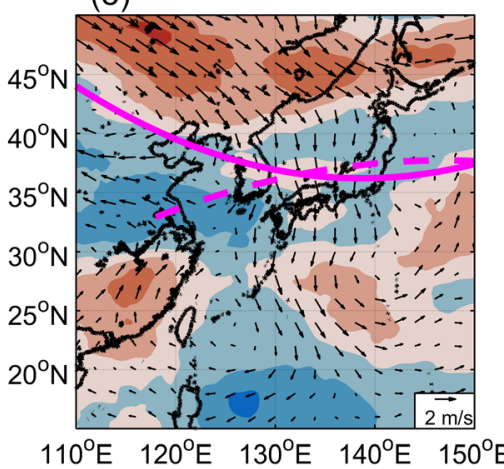

(h)

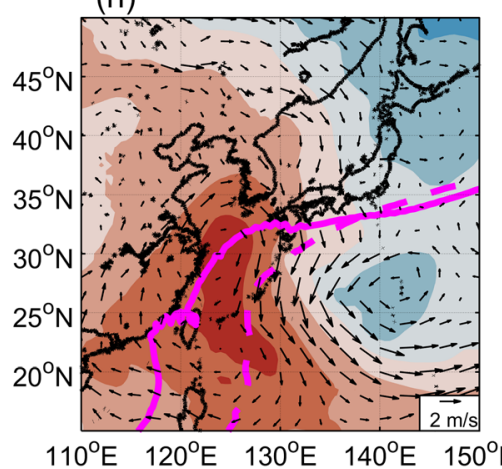

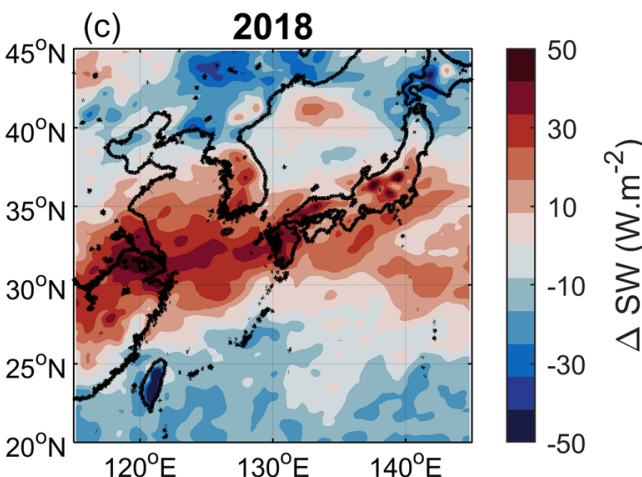
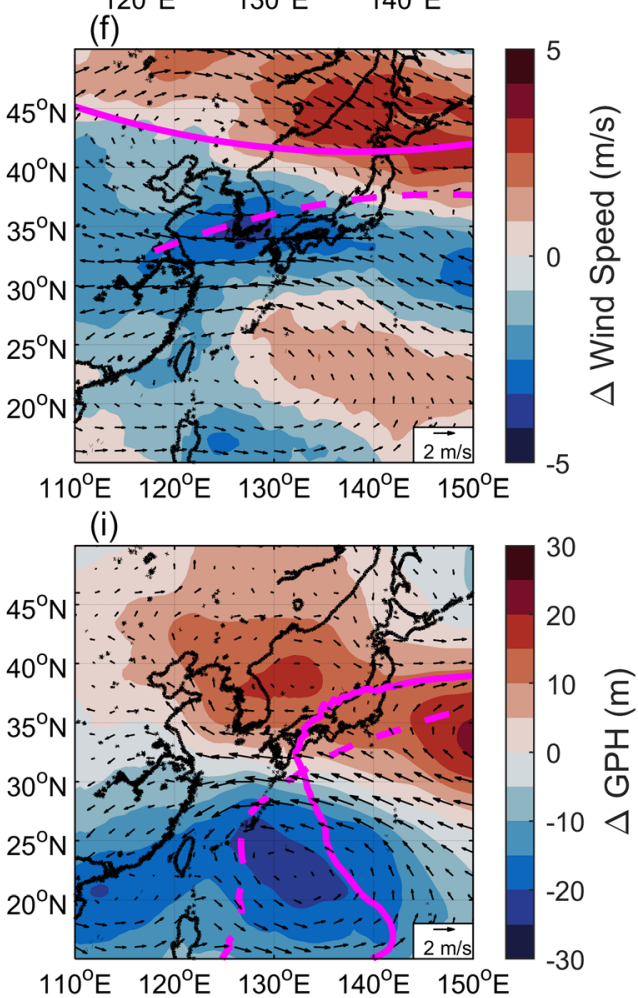

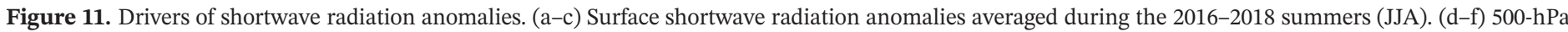
wind speed (shading) and wind direction (vectors) anomalies. The climatological (dashed) and averaged (solid) position of the 500-hPa jet is plotted in

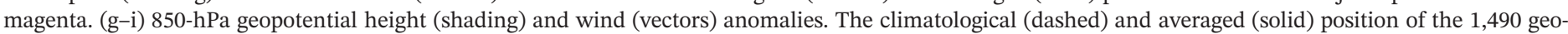
potential height contour is plotted in magenta. The 2013-2015 normal years JJA averages were defined as the climatology.

via a decrease of moisture transport and/or horizontal thermal gradient (Ding \& Chan, 2005; S.-S. Lee et al., 2013) or shifted the location of the Meiyu-Baiu front (Q. Gao et al., 2016).

The mid-level East Asian Westerly Jet (EAWJ) was also found to have a profound impact on the EASM. Several studies showed that the position of the EAWJ impacted the amount of precipitation in the Yangtze River Basin (Du et al., 2009; S. Xuan et al., 2011). Recently, the EAWJ intensity was found to be positively correlated with precipitation in the Yangtze River Basin (S. Wang \& Zuo, 2016). Anomalies of winds at $500 \mathrm{hPa}$ showed that the EAWJ was weaker in 2017 and shifted northward in 2016 and 2018 (Figures 11d-11f), helping to weaken the frontal system and increase shortwave radiation irradiance.

Despite the roles that both the WPSH and the EAWJ likely played in increasing shortwave irradiance during the summer of 2016-2018, our understanding of the complex EASM system remains limited. Further research is needed to explain the recent increases of summer shortwave radiations over the ECSs. 

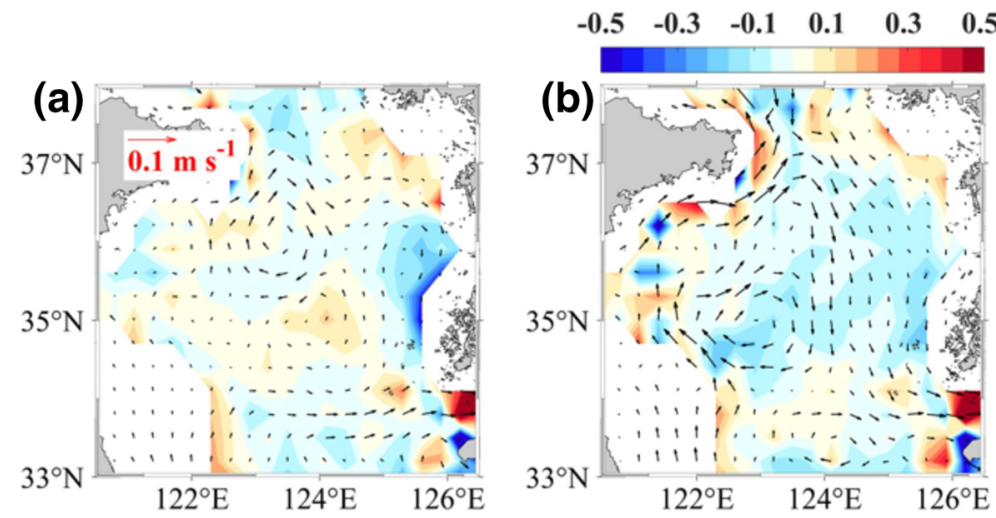

$10^{-5} \mathrm{~m} \mathrm{~s}^{-1}$
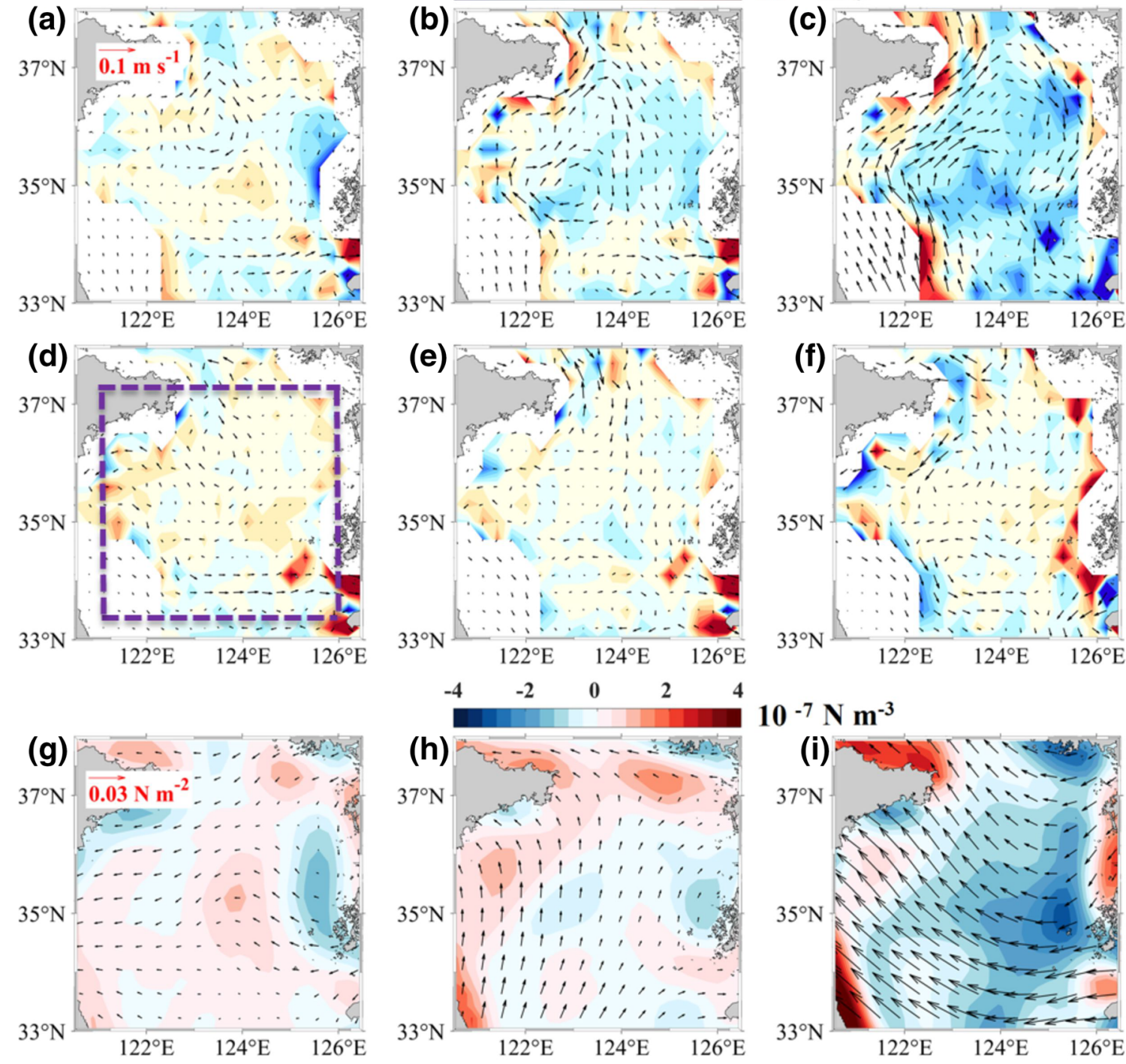

2016, Jun 1 to Aug 26

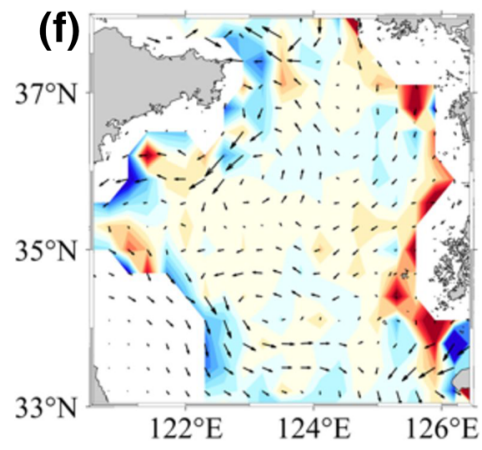

$100^{-7} \mathrm{~N} \mathrm{~m}^{-3}$

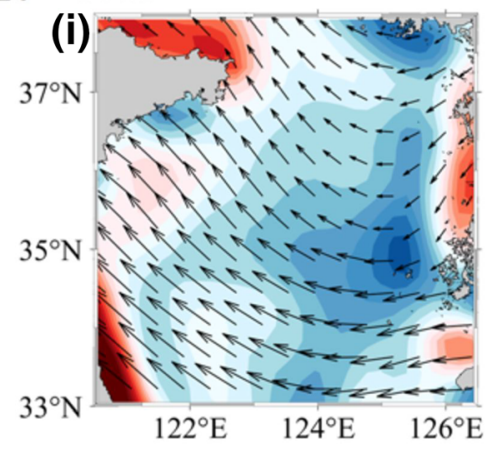

2018, Jun 1 to Aug 17

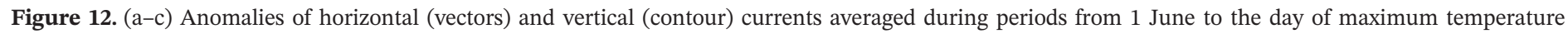

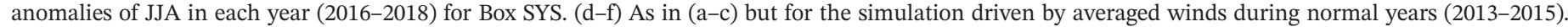

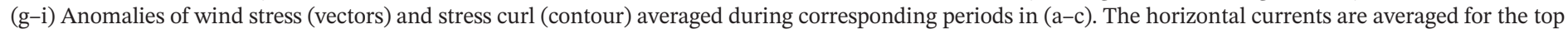
$20 \mathrm{~m}$ and the vertical currents are at $20 \mathrm{~m}$.

\subsection{Ocean Currents}

Since the contribution of advection to the anomalous warming is determined by the variability of ocean currents and temperature, the effects of current anomalies played a more important role than those due to temperature anomalies for both Boxes (Figures S12 and S13). Thus, in this section, we further examine the effects of current anomalies during the three warm summers.

As shown in Figure S11a, the FVCOM-ECSs has successfully reproduced the cyclonic circulation (jet-like southward currents in the west portion and northward currents in the east portion of the central trough) in the SYS (Beardsley et al., 1992; Xia et al., 2006; Yanagi \& Takahashi, 1993), northward currents along the Chinese coast (Naimie et al., 2001), and the TWC and TsWC system (Isobe, 2004, 2008). Current anomalies averaged during JJA were much prominent in 2018 than those in 2016 and 2017. 

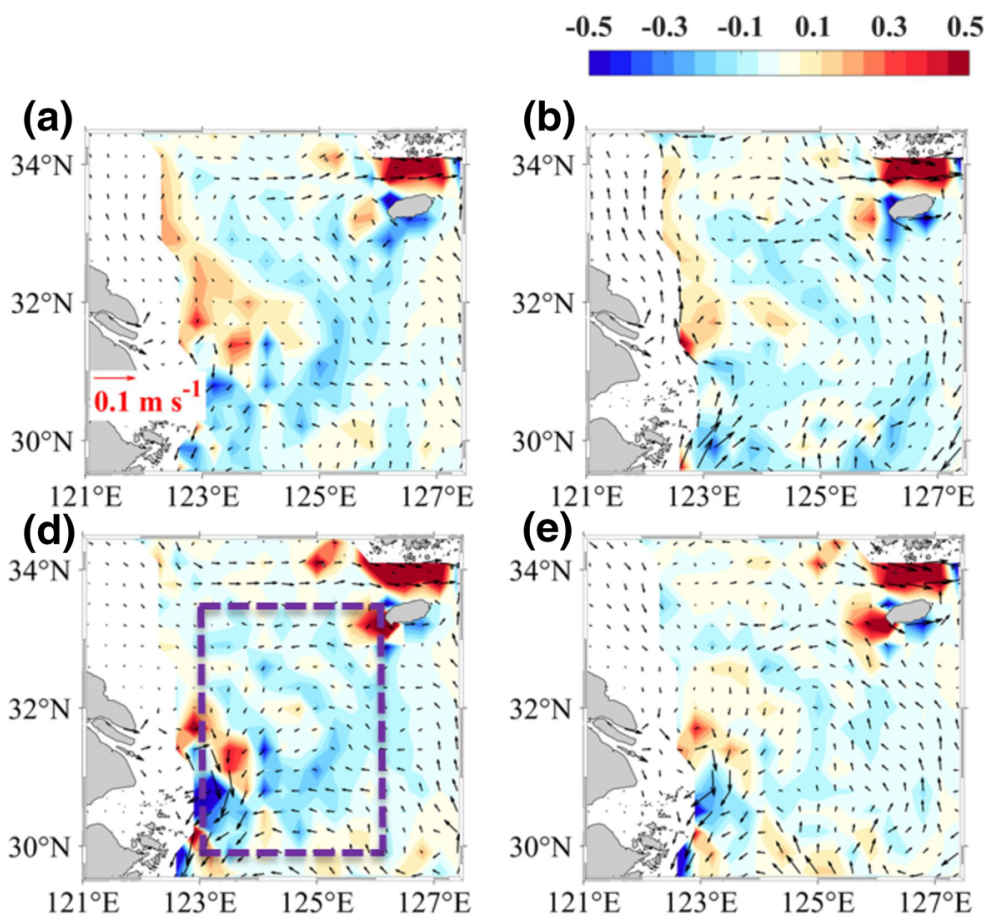

(b)

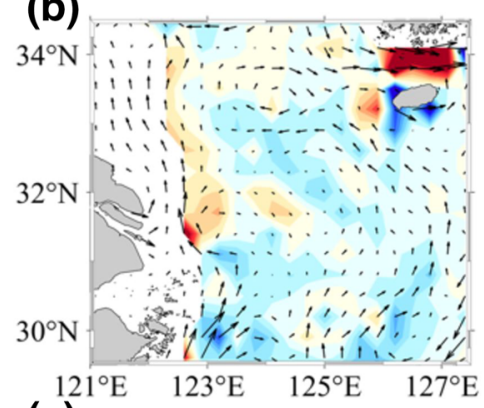

(e)
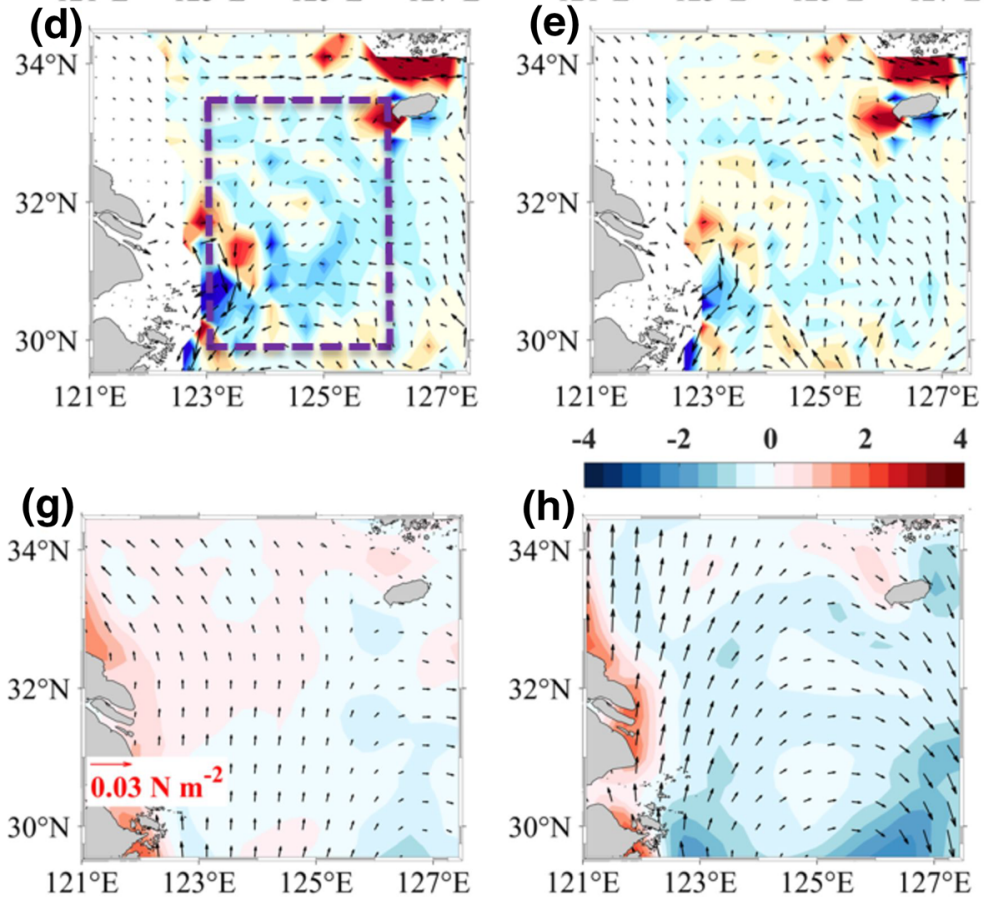

2016, Jun 1 to Aug 17

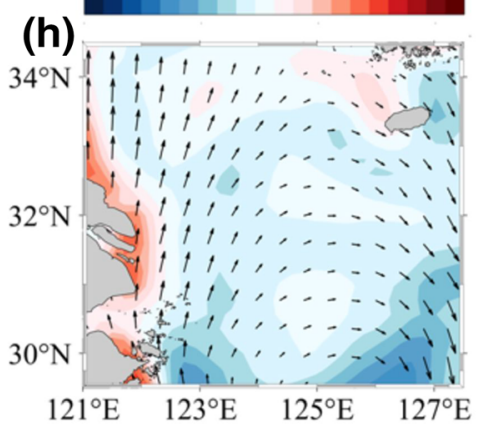

2017, Jun 1 to Aug 7
$10^{-5} \mathrm{~m} \mathrm{~s}^{-1}$

(c)
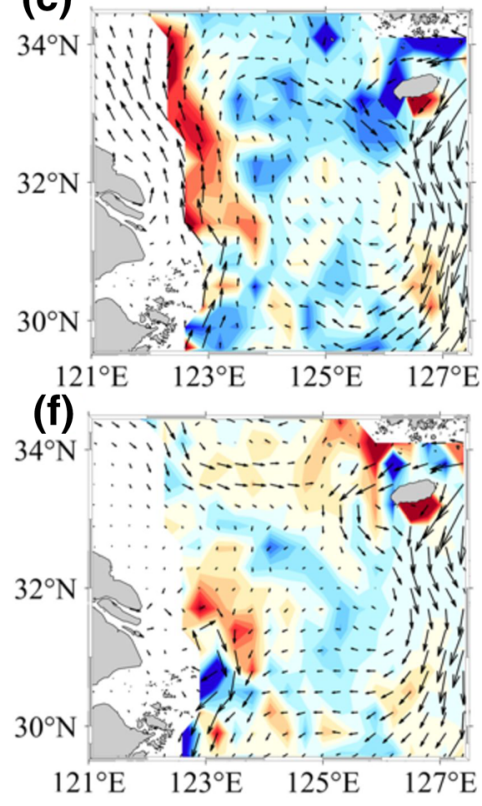

$10^{-7} \mathrm{~N} \mathrm{~m}^{-3}$

(i)

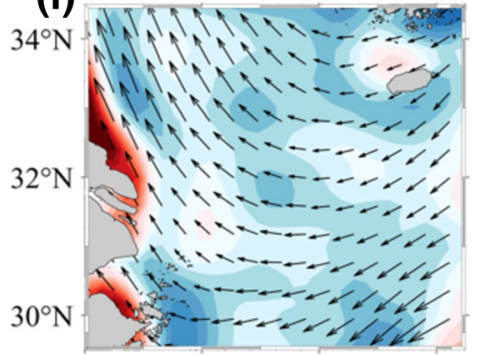

$121^{\circ} \mathrm{E} \quad 123^{\circ} \mathrm{E} \quad 125^{\circ} \mathrm{E} \quad 127^{\circ} \mathrm{E}$

2018, Jun 1 to Jul 20

Figure 13. As in Figure 12 but for Box NECS.

For a better illustration, current anomalies during the periods from 1 June to the day when peak temperature anomalies occurred during JJA in each year (2016-2018) are plotted in Figures 12a-12c (Box SYS) and Figures 13a-13c (Box NECS). The anomalies of wind stress and stress curls averaged during corresponding periods are shown in Figures 12g-12i (Box SYS) and Figures 13g-13i (Box NECS). Normal-year averages (2013-2015) and anomalies (2016-2018) of wind stress and wind stress curls averaged during JJA can be seen in Figure S14. To investigate the local wind effects on the current system, we conducted a model run (Experiment 1) in which we replaced the wind forcing in JJA 2016-2018 with the normal-year averaged wind forcing (2013-2015 average) and then analyzed the current anomalies averaged during the corresponding periods (Figures 12d-12f and 13d-13f).

\section{Box SYS}

In 2017, anomalous downwelling covered more than half of Box SYS and northward current anomalies were found in the west part of south boundary (Figure 12b), where temperatures were higher than the box average, both contributing to the maximum temperature anomalies of Box SYS. In 2018, anticylonic current anomalies and downwelling dominated the whole Box SYS (Figure 12c). Northward current anomalies 
(a)

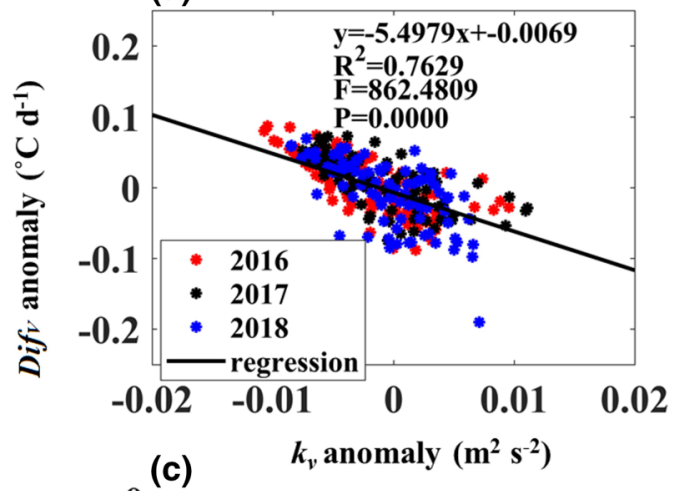

(b)
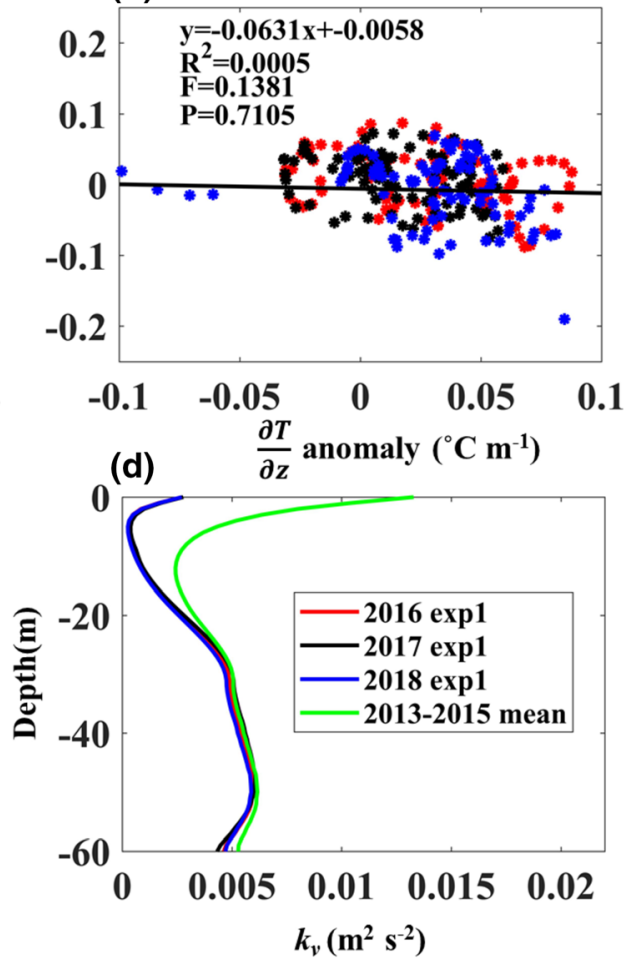

Figure 14. Anomalies (2016-2018) of daily temperature changes due to vertical mixing are plotted against the anomalies of daily-averaged (a) vertical eddy viscosities and (b) vertical temperature gradients at $20 \mathrm{~m}$ in Box NECS. (c) Vertical profile of JJA-mean vertical eddy viscosities in Box NECS. (d) As in (c) but for Experiment 1. 2013-2015 mean vertical eddy viscosities in (d) were same as that in (c). The corresponding statistical estimators are also given in (a) and (b).

were significant at the south boundary as well. Therefore, advection in the south and vertical boundaries contributed to more than half of the maximum temperature anomalies of Box SYS in 2018. The current anomalies were absent in Experiment 1 (Figures 12d-12f), confirming that current anomalies in Box SYS were due to the regional wind anomalies.

\section{Box NECS}

Northward currents along the Chinese coast $\left(31-35^{\circ} \mathrm{N}\right.$; west to $\left.124^{\circ} \mathrm{E}\right)$ were strengthened (Figures $13 \mathrm{~b}$ and 13c) by the anomalous northward winds (Figures 13h and 13i) in both 2017 and 2018, which transported more heat into Box NECS from the south or west boundary. The anomalous wind stress curl also drove downwelling anomalies in 2018 (Figure 13c), contributing to the anomalous warming.

In 2017, strengthened northeastward currents were found between $125^{\circ} \mathrm{E}$ and $127^{\circ} \mathrm{E}$ in the east part of Box NECS, which transported more heat out of Box NECS at the east boundary (Figure 13b). However, current anomalies were southwestward between $125^{\circ} \mathrm{E}$ and $127^{\circ} \mathrm{E}$ in 2018 (Figure 13c) and were not sensitive to the local wind anomalies. Thus, currents anomalies between $125^{\circ} \mathrm{E}$ and $127^{\circ} \mathrm{E}$ were likely due to interannual variations of the TsWCs. The TsWC on the shelf of the ECS originates from TWC and intrusions from the KC (Fan, 1982; Guan \& Fang, 2006; Guo et al., 2006; Ma et al., 2010). The TsWC variability is primarily forced by the open ocean processes through the KC rather than TWC (Ma et al., 2010; J. Yang, 2007; Zheng et al., 2009).

\subsection{Vertical Mixing}

Figures 14a and 14b show that anomalies of daily temperature changes in Box NECS during three warm summers were remarkably well correlated with vertical diffusion anomalies, other than vertical temperature gradient anomalies. From the model, vertical diffusion at 20-m depth averaged during JJA was reduced in 2016 and 2017 and enhanced in 2018 (Figure 14c); thus, the vertical mixing anomalies contributed to the 
anomalous warming in 2016 and 2017 but not in 2018. Surface winds play a major role in driving the vertical mixing in the upper layer of the ECSs (S. Park \& Chu, 2007; J. L. Xuan et al., 2012). Note the magnitudes of wind speeds in Box NECS were reduced in 2016 and 2017 but increased in 2018 (Figures S6d-S6g). Temperature anomalies in Box NECS had a sharp decrease near the end of August in 2018 (Figure 9d), which was probably related to the enhanced vertical mixing associated with the passage of Typhoon Soulik.

When the model was driven by the normal-year averaged wind speeds (Experiment 1), the vertical diffusion had negligible differences among three warm summers (Figure 14d). This further confirms the role of wind speed anomalies on the anomalous vertical mixing. Note that magnitudes of winds speeds in Experiment 1 were smaller than the normal year (Figure S15); thus, the vertical eddy diffusions (2016-2018) in Experiment 1 were weaker than the normal year averages (Figure 14d).

\section{Summary and Conclusion}

The ECSs (ECS and the SYS) experienced unprecedented MHW events during three consecutive summers from 2016 to 2018. Using the outputs from a well-validated hydrodynamics model with high spatial resolutions, we investigated the roles of oceanic processes and air-sea heat flux in controlling the anomalous upper ocean warming in two regions in the ECSs. Temperature budgets for the top $20 \mathrm{~m}$ in Boxes SYS and NECS illustrate that these warm summers were associated with variations of shortwave radiation, advection, and vertical mixing. Positive shortwave radiation anomalies during JJA from 2016 to 2018 were associated with the reduction of cloud covers in the Meiyu-Baiu front/rain region, and both the intensity and position of the WPSH and EAWJ likely contributed to the weakening and/or northward shift of Meiyu-Baiu front/rainband associated with the EASM. Northward current anomalies transported more heat into Boxes SYS and NECS from the south boundary during the three summers. Downwelling anomalies dominated Box SYS in 2018, which significantly enhanced the warming of the surface layer. Over whole Box SYS and west part of Box NECS, currents anomalies in both horizontal and vertical directions were forced by the anomalous wind stress and stress curls. In addition, reductions in the magnitudes of wind speeds over Box NECS weakened the local vertical mixing and significantly intensified the anomalous warming in 2016 and 2017. These wind anomalies are also likely associated with the monsoon variations. This research highlights that a high-resolution ocean modeling is important to understand the local and remote processes in the driving the MHWs in the coastal regions. The identification of roles of the East Asian Monsoon system in the MHW development in the ECSs may help understand MHW dynamics in other coastal regions at middle latitudes where the monsoon system is dominant during the summer season.

\section{Data Availability Statement}

The FVCOM-ECSs model data are available from the Marine Science Data Center of Institute of Oceanology, Chinese Academy of Sciences (http://159.226.158.89:38817/thredds/catalog/Ggd/catalog.html).

\section{Acknowledgments}

This work was supported by the National Natural Science Foundation of Shandong Province (no. 41406097) and CAS-CSIRO collaborative funding. The work was also supported by the Strategic Priority Research Program of the Chinese Academy of Sciences (XDB42000000) and NSFC- Shandong Joint Fund (U1806227). Dezhou Yang was supported by the National Natural Science Foundation of China (NSFC) (41576023 and 41876019). Yang Ding was supported by the National Natural Science Foundation of China (no. 41430963). We thank the anonymous reviewers for commenting on the early draft of the paper.

\section{References}

Asbjørnsen, H., Årthun, M., Skagseth, Ø., \& Eldevik, T. (2019). Mechanisms of ocean heat anomalies in the Norwegian Sea. Journal of Geophysical Research: Oceans, 124, 2908-2923. https://doi.org/10.1029/2018JC014649

Beardsley, R. C., Limeburner, R., Kim, K., \& Candela, J. (1992). Lagrangian flow observations in the East China. Yellow and Japan Seas, La Mer, 30, 297-314.

Behringer, D. (2007). The Global Ocean Data Assimilation System (GODAS) at NCEP, 87th AMS Annual Meeting.

Benthuysen, J., Feng, M., \& Zhong, L. (2014). Spatial patterns of warming off Western Australia during the 2011 Ningaloo Niño: Quantifying impacts of remote and local forcing. Continental Shelf Research, 91, 232-246. https://doi.org/10.1016/j. csr.2014.09.014

Benthuysen, J. A., Oliver, E. C. J., Feng, M., \& Marshall, A. G. (2018). Extreme marine warming across tropical Australia during austral summer 2015-16. Journal of Geophysical Research: Oceans, 123, 1301-1326. https://doi.org/10.1002/2017JC013326

Bond, N. A., Cronin, M. F., Freeland, H., \& Mantua, N. (2015). Causes and impacts of the 2014 warm anomaly in the NE Pacific. Geophysical Research Letters, 42, 3414-3420. https://doi.org/10.1002/2015GL063306

Cai, R., Tan, H., \& Kontoyiannis, H. (2017). Robust surface warming in offshore China seas and its relationship to the east Asian monsoon wind field and ocean forcing on interdecadal time scales. Journal of Climate, 30(22), 8987-9005. https://doi.org/10.1175/JCLI-D-160016.1

Cai, R., Tan, H., \& Qi, Q. (2016). Impacts of and adaptation to inter-decadal marine climate change in coastal China seas. International Journal of Climatology, 36(11), 3770-3780. https://doi.org/10.1002/joc.4591

Caputi, N., Kangas, M., Denham, A., Feng, M., Pearce, A., Hetzel, Y., et al. (2016). Management adaptation of invertebrate fisheries to an extreme marine heatwave event at a global warming hot spot. Ecology and Evolution, 6(11), 3583-3593. https://doi.org/10.1002/ ece 3.2137 
Chen, C., Beardsley, R. C., Cowles, G., Qi, J., Lai, Z., Gao, G., et al. (2013). An unstructured grid, finite-volume community ocean model FVCOM user manual, SMAST/UMASSD-13-0701.

Chen, C., Liu, H., \& Beardsley, R. C. (2003). An unstructured grid, finite volume, three-dimensional, primitive equations ocean model: Application to coastal ocean and estuaries. Journal of Atmospheric \& Oceanic Technology, 20, 159-186. https://doi.org/10.1175/15200426(2003)020,0159:AUGFVT.2.0.CO;2

Chen, K., Gawarkiewicz, G. G., Lentz, S. J., \& Bane, J. M. (2014). Diagnosing the warming of the Northeastern US Coastal Ocean in 2012: A linkage between the atmospheric jet stream variability and ocean response. Journal of Geophysical Research: Oceans, 119, $218-227$. https://doi.org/10.1002/2013JC009393

Di Lorenzo, E., \& Mantua, N. (2016). Multi-year persistence of the 2014/15 North Pacific marine heatwave. Nature Climate Change, 6(11), 1042-1047. https://doi.org/10.1038/nclimate3082

Ding, Y., Bao, X., Yao, Z., Bi, C., Wan, K., Bao, M., et al. (2019). Observational and model studies of synoptic current fluctuations in the Bohai Strait on the Chinese continental shelf. Ocean Dynamics, 69(3), 323-351. https://doi.org/10.1007/s10236-019-01247-5

Ding, Y., Bao, X., Yao, Z., Song, D., Song, J., Gao, J., et al. (2018). Effect of coastal-trapped waves on the synoptic variations of the Yellow Sea Warm Current during winter. Continental Shelf Research, 167, 14-31. https://doi.org/10.1016/j.csr.2018.08.003

Ding, Y., \& Chan, J. C. L. (2005). The East Asian Summer Monsoon: An overview. Meteorology \& Atmospheric physics, 89, 117-142.

Ding, Y., Yu, H. M., Bao, X. W., Kuang, L., Wang, C. X., \& Wang, W. J. (2011). Numerical study of the barotropic responses to a rapidly moving typhoon in the East China Sea. Ocean Dynamics, 61, 1237-1259. https://doi.org/10.1007/s10236-011-0436-1

Du, Y., Zhang, Y., \& Xie, Z. (2009). Impacts of the zonal position of the East Asian Westerly Jet core on precipitation distribution during Meiyu of China. Acta Meteorologica: Sinica.

Fairall, C. W., Bradley, E. F., Rogers, D. P., Edson, J. B., \& Young, G. S. (1996). Bulk parameterization of air-sea fluxes for tropical ocean-global atmosphere coupled-ocean atmosphere response experiment. Journal of Geophysical Research, 101(C2), 3747-3764. https:// doi.org/10.1029/95JC03205

Fan, K. L. (1982). A study of water masses in Taiwan Strait. Acta Oceanographica Taiwanica, 13, 140-153.

Fathrio, I., Iizuka, S., Manda, A., Kodama, Y.-M., Ishida, S., Moteki, Q., et al. (2017). Assessment of western Indian Ocean SST bias of CMIP5 models. Journal of Geophysical Research, 122, 3123-3140. https://doi.org/10.1002/2016JC012443

Feng, M., Biastoch, A., Böning, C., Caputi, N., \& Meyers, G. (2008). Seasonal and interannual variations of upper ocean heat balance off the west coast of Australia. Journal of Geophysical Research: Oceans, 113, C12025. https://doi.org/10.1029/2008JC004908

Feng, M., McPhaden, M. J., Xie, S. P., \& Hafner, J. (2013). La Niña forces unprecedented Leeuwin Current warming in 2011. Scientific Reports, 3(1), 1277. https://doi.org/10.1038/srep01277

Frölicher, T. L., Fischer, E. M., \& Gruber, N. (2018). Marine heatwaves under global warming. Nature, 560, 360-364. https://doi.org/ 10.1038/s41586-018-0383-9

Gao, G. D., Wang, X. H., Song, D. H., Bao, X. W., Yin, B. S., Yang, D. Z., et al. (2018). Effects of wave-current interactions on suspended-sediment dynamics during strong wave events in JiaozhouBay, Qingdao China. Journal of Physical Oceanography, 48, 1053-1078. https://doi.org/10.1175/JPO-D-17-0259.1

Gao, Q., Sun, Y., \& You, Q. (2016). The northward shift of Meiyu rain belt and its possible association with rainfall intensity changes and the Pacific-Japan pattern. Dynamics of Atmospheres and Oceans, 76, 52-62. https://doi.org/10.1016/j.dynatmoce.2016.08.005

Guan, B. X., \& Fang, G. H. (2006). Winter counter-wind currents off the southeastern China coast: A review. Journal of Oceanography, 62(1), 1-24. https://doi.org/10.1007/s10872-006-0028-8

Hobday, A. J., Alexander, L. V., Perkins, S. E., Smale, D. A., Straub, S. C., Oliver, E. C., et al. (2016). A hierarchical approach to defining marine heatwaves. Progress in Oceanography, 238, 141, 227. https://doi.org/10.1016/j.pocean.2015.12.014

Hristova, H. G., Ladd, C., \& Stabeno, P. J. (2019). Variability and trends of the Alaska Gyre from Argo and Satellite Altimetry. Journal of Geophysical Research: Oceans, 124, 5870-5887. https://doi.org/10.1029/2019JC015231

Huang, Y., Wang, B., Li, X., \& Wang, H. (2018). Changes in the influence of the western Pacific subtropical high on Asian summer monsoon rainfall in the late 1990s. Climate Dynamics, 51(1-2), 443-455. https://doi.org/10.1007/s00382-017-3933-1

Isobe, A. (2004). Driving mechanism of band structure of mean current over the continental shelf. Journal of Physical Oceanography, 34(8), 1839-1855. https://doi.org/10.1175/1520-0485(2004)034<1839:DMOBSO > 2.0.CO;2

Isobe, A. (2008). Recent advances in ocean-circulation research on the Yellow Sea and East China Sea shelves. Journal of Oceanography, 64(4), 569-584. https://doi.org/10.1007/s10872-008-0048-7

Jacox, M. G. (2019). Marine heatwaves in a changing climate. Nature, 571(7766), 485-487. https://doi.org/10.1038/d41586-019-02196-1

Kanamitsu, M., Ebisuzaki, W., Woollen, J., Yang, S.-K., Hnilo, J. J., Fiorino, M., \& et al. (2002). NCEP-DOE AMIP-II reanalysis (R-2). Bulletin of the American Meteorological Society, 83(11), 1631-1644. https://doi.org/10.1175/BAMS-83-11-1631

Lee, S.-S., Seo, Y.-W., Ha, K.-J., \& Jhun, J.-G. (2013). Impact of the western North Pacific subtropical high on the East Asian monsoon precipitation and the Indian Ocean precipitation in the boreal summertime. Asia-Pacific Journal of Atmospheric Sciences, 49(2), 171-182. https://doi.org/10.1007/s13143-013-0018-x

Lee, T., Fukumori, I., \& Tang, B. (2004). Temperature advection: Internal versus external processes. Journal of Physical Oceanography, 34(8), 1936-1944. https://doi.org/10.1175/1520-0485(2004)034<1936:TAIVEP >2.0.CO;2

Lozovatsky, I. D., Liu, Z., \& Fernando, H. J. S. (2007a). Tides and mixing in the northwestern East China Sea. Part I: Rotating and reversing tidal flows, Continental Shelf Research, 28(2), 318-337. https://doi.org/10.1016/j.csr.2007.08.006

Lozovatsky, I. D., Liu, Z., \& Fernando, H. J. S. (2007b). Tides and mixing in the northwestern East China Sea, part II: Near-bottom turbulence. Continental Shelf Research, 28(2), 338-350. https://doi.org/10.1016/j.csr.2007.08.007

Ma, C., Wu, D. X., Lin, X., Yang, J., \& Ju, X. (2010). An open-ocean forcing in the East China and Yellow seas. Journal of Geophysical Research, 115(C12), C12056. https://doi.org/10.1029/2010JC006179

Matsumura, S., Sugimoto, S., \& Sato, T. (2015). Recent intensification of the western Pacific subtropical high associated with the East Asian Summer Monsoon. Journal of Climate, 28(7), 2873-2883. https://doi.org/10.1175/JCLI-D-14-00569.1

Mellor, G. L., \& Yamada, T. (1982). Development of a turbulence closure model for geophysical fluid problems. Reviews of Geophysics, 20(4), 851-875. https://doi.org/10.1029/RG020i004p00851

Menemenlis, D., Campin, J. M., Heimbach, P., Hill, C., Lee, T., Nguyen, A., et al. (2008). ECCO2: High resolution global ocean and sea ice data synthesis. Mercator Ocean Quarterly Newsletter, 31, 13-21.

Mills, K. E., Pershing, A. J., Brown, C. J., Chen, Y., Chiang, F.-S., Holland, D. S., et al. (2012). Lessons from the 2012 ocean heatwave in the Northwest Atlantic. Oceanography, 26, 60-64.

Naimie, C. E., Blain, C. A., \& Lynch, D. R. (2001). Seasonal mean circulation in the Yellow Sea-A model-generated climatology. Continental Shelf Research, 21(6-7), 667-695. https://doi.org/10.1016/S0278-4343(00)00102-3 
Ninomiya, K. (2004). Large- and mesoscale features of Meiyu-Baiu front associated with intense rainfalls. pp. 404-435. https://doi.org/ 10.1142/9789812701411_0011

Oey, L.-Y., Chang, M.-C., Chang, Y.-L., Lin, Y.-C., \& Xu, F.-H. (2013). Decadal warming of coastal China seas and coupling with winter monsoon and currents. Geophysical Research Letters, 40, 6288-6292. https://doi.org/10.1002/2013GL058202

Olita, A., Sorgente, R., Ribotti, A., Natale, S., \& Gaberšek, S. (2006). Effects of the 2003 European heatwave on the Central Mediterranean Sea surface layer: A numerical simulation. Ocean Science, 3, 85-125.

Oliver, E. C. J. (2019). Mean warming not variability drives marine heatwave trends. Climate Dynamics, 53(3-4), 1653-1659. https://doi.org/ 10.1007/s00382-019-04707-2

Oliver, E. C. J., Benthuysen, J. A., Bindoff, N. L., Hobday, A. J., Holbrook, N. J., Munday, C. N., et al. (2017). The unprecedented 2015/16 Tasman Sea marine heatwave. Nature Communications, 8, 16101. https://doi.org/10.1038/ncomms16101

Oliver, E. C. J., Donat, M. G., Burrows, M. T., Moore, P. J., Smale, D. A., Alexander, L. V., et al. (2018). Longer and more frequent marine heatwaves over the past century. Nature Communications, 9(1), 1324. https://doi.org/10.1038/s41467-018-03732-9

Oppenheim, A. V., Schafer, R. W., \& Buck, J. R. (1999). Discrete-time signal processing. (2Nd ed.). Upper Saddle River, NJ, USA: Prenticehall, Inc.

Park, C., \& Schubert, S. D. (1994). On the nature of the 1994 East Asian summer drought. Journal of Climate, 10, 1056-1070.

Park, K. A., Lee, E. Y., Chang, E., \& Hong, S. (2015). Spatial and temporal variability of sea surface temperature and warming trends in the Yellow Sea. Journal of Marine Systems, 143, 24-38. https://doi.org/10.1016/j.jmarsys.2014.10.013

Park, S., \& Chu, P. C. (2007). Synoptic distributions of thermal surface mixed layer and thermocline in the southern Yellow and East China seas. Journal of Oceanography, 63(6), 1021-1028. https://doi.org/10.1007/s10872-007-0085-7

Paulson, C. A., \& Simpson, J. J. (1977). Irradiance measurements in the upper ocean. Journal of Physical Oceanography, 7(6), 952-956. https://doi.org/10.1175/1520-0485(1977)007<0952:IMITUO>2.0.CO;2

Reynolds, R. W., Smith, T. M., Liu, C., Chelton, D. B., Casey, K. S., \& Schlax, M. G. (2007). Daily high-resolution-blended analyses for sea surface temperature. Journal of Climate, 20(22), 5473-5496. https://doi.org/10.1175/2007JCLI1824.1

Saha, S., Moorthi, S., Pan, H.-L., Wu, X., Wang, J., Nadiga, S., et al. (2010). The NCEP climate forecast system reanalysis. Bulletin of the American Meteorological Society, 91, 1015-1058.

Saha, S., Moorthi, S., Wu, X., Wang, J., Nadiga, S., Tripp, P., et al. (2013). The NCEP Climate Forecast System Version 2. Journal of Climate, 27(6), 2185-2208. https://doi.org/10.1175/JCLI-D-12-00823.1

Schlegel, R. W., Oliver, E. C. J., Perkins-Kirkpatrick, S., Kruger, A., \& Smit, A. J. (2017). Predominant atmospheric and oceanic patterns during coastal marine heatwaves. Frontier Marine Science, 4, 323. https://doi.org/10.3389/fmars.2017.00323

Smagorinsky, J. (1963). General circulation experiments with the primitive equations, I. The basic experiment. Monthly Weather Review, 91 , 99-164.

Sparnocchia, S., Schiano, M. E., Picco, P., Bozzano, R., \& Cappelletti, A. (2006). The anomalous warming of summer 2003 in the surface layer of the Central Ligurian Sea (Western Mediterranean). Annales Geophysicae, 24(2), 443-452. https://doi.org/10.5194/angeo-24-443-2006

Tan, H., \& Cai, R. (2018). What caused the record-breaking warming in East China seas during August 2016? Atmospheric Sciences Letters, 19, e853. https://doi.org/10.1002/asl.853

US Naval Oceanographic Office and the US Naval Ocean Research and Development Activity. (1983). DBDB5 (Digital Bathymetric Data Base-5 Minute Grid). US N.O.O., Bay St. Louis, p 329.

Wang, B., Xiang, B., \& Lee, J.-Y. (2013). Subtropical High predictability establishes a promising way for monsoon and tropical storm predictions. Proceedings of the National Academy of Sciences of the United States of America, 110, 2718 LP-2722. https://doi.org/10.1073/ pnas. 1214626110

Wang, J., \& Oey, L.-Y. (2014). Inter-annual and decadal fluctuations of the Kuroshio in East China Sea and connection with surface fluxes of momentum and heat. Geophysical Research Letters, 41, 8538-8546. https://doi.org/10.1002/2014GL062118

Wang, S., \& Zuo, H. (2016). Effect of the East Asian Westerly Jet's intensity on summer rainfall in the Yangtze River Valley and its mechanism. Journal of Climate, 29(7), 2395-2406. https://doi.org/10.1175/JCLI-D-15-0259.1

Xia, C., Qiao, F., Yang, Y., Ma, J., \& Yuan, Y. (2006). Three-dimensional structure of the summertime circulation in the Yellow Sea from a wave-tide-circulation coupled model. Journal of Geophysical Research, 111, C11S03. https://doi.org/10.1029/2005JC003218

Xie, S., Hafner, J., Tanimoto, Y., Liu, W. T., Tokinaga, H., \& Xu, H. (2002). Bathymetric effect on the winter sea surface temperature and climate of the Yellow and East China seas. Geophysical Research Letters, 29(24), 2228. https://doi.org/10.1029/2002GL015884

Xuan, J. L., Huang, D. J., Zhou, F., Zhu, X., \& Fan, X. P. (2012). The role of wind on the detachment of low salinity water in the Changjiang Estuary in summer. Journal of Geophysical Research, 117, C10004. https://doi.org/10.1029/2012JC008121

Xuan, S., Zhang, Q., \& Sun, S. (2011). Anomalous midsummer rainfall in Yangtze River-Huaihe River valleys and its association with the East Asia Westerly Jet. Advances in Atmospheric Science, 28, 387-397. https://doi.org/10.1007/s00376-010-0111-3

Yanagi, T., \& Takahashi, S. (1993). Seasonal variation of circulations in the East China Sea and the Yellow Sea. Journal of the Oceanographic Society of Japan, 49, 491-501.

Yang, D. Z., Huang, R. X., Yin, B. S., Feng, X.-R., Chen, H. Y., Qi, J. F., et al. (2018). Topographic beta spiral and onshore intrusion of the Kuroshio Current. Geophysical Research Letters, 45, 287-296. https://doi.org/10.1002/2017GL076614

Yang, J. (2007). An oceanic current against the wind: How does TaiwanIsland steer warm water into the East China Sea. Journal of Physical Oceanography, 37(10), 2563-2569. https://doi.org/10.1175/JPO3134.1

Yeh, S.-W., \& Kim, C.-H. (2010). Recent warming in the Yellow/East China Sea during winter and the associated atmospheric circulation. Continental Shelf Research, 30(13), 1428-1434. https://doi.org/10.1016/j.csr.2010.05.002

Zhang, Y., Feng, M., Du, Y., Phillips, H. E., Bindoff, N. L., \& McPhaden, M. J. (2018). Strengthened Indonesian Throughflow drives decadal warming in the Southern Indian Ocean. Geophysical Research Letters, 45, 6167-6175. https://doi.org/10.1029/2018GL078265

Zheng, P., Wu, D., \& Lin, X. (2009). the relationship between the Taiwan Warm Current and Tsushima Warm Current. Journal of Hydrodynamics, 21(2), 212-218. https://doi.org/10.1016/S1001-6058(08)60138-9

Zhou, T., Gong, D., Li, J., \& Li, B. (2009). Detecting and understanding the multi-decadal variability of the East Asian Summer Monsoon recent progress and state of affairs. Meteorologische Zeitschrift, 18(4), 455-467. https://doi.org/10.1127/0941-2948/2009/0396 